Discussion Paper No. 07-044

\title{
Independence and Accountability of Monetary and Fiscal Policy Committees
}

Alexander Mihailov and Katrin Ullrich

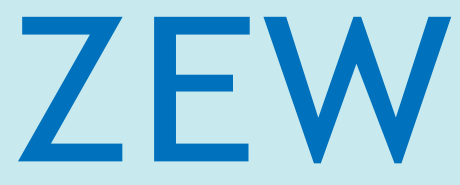

Zentrum für Europäische Wirtschaftsforschung $\mathrm{GmbH}$

Centre for European

Economic Research 
Discussion Paper No. 07-044

\title{
Independence and Accountability of Monetary and Fiscal Policy Committees
}

\author{
Alexander Mihailov and Katrin Ullrich
}

Download this ZEW Discussion Paper from our ftp server:

ftp://ftp.zew.de/pub/zew-docs/dp/dp07044.pdf

Die Discussion Papers dienen einer möglichst schnellen Verbreitung von neueren Forschungsarbeiten des ZEW. Die Beiträge liegen in alleiniger Verantwortung der Autoren und stellen nicht notwendigerweise die Meinung des ZEW dar.

Discussion Papers are intended to make results of ZEW research promptly available to other economists in order to encourage discussion and suggestions for revisions. The authors are solely responsible for the contents which do not necessarily represent the opinion of the ZEW. 


\title{
Independence and Accountability of Monetary and Fiscal Policy Committees
}

\author{
Alexander Mihailov* and Katrin Ullrich ${ }^{\dagger}$ \\ This version: July $2007^{\ddagger}$ \\ First draft: January 2007
}

\begin{abstract}
The democratic accountability of policymaking institutions which are autonomous within delegated mandates has not received as much attention as their independence. We analyze in a theoretical model the effects of accountability in the form of possible overriding of economic policy decisions by the government under different degrees of independence of expert committees conducting monetary and fiscal policy. The equilibrium outcomes of such alternative institution-design frameworks are compared according to key macroeconomic performance criteria. Our results stress the trade-off between anchoring inflation expectations on target and output stabilization that is not solved with accountability.
\end{abstract}

JEL Classification: E52, E58, E61, E63

Key Words: Independence, accountability, monetary policy, fiscal policy, expert committees, institution design

*Department of Economics, University of Reading, P.O. Box 218, Whiteknights, Reading RG6 6AA, United Kingdom; a.mihailov@reading.ac.uk. The author is currently also a visiting lecturer at the Department of Economics, City University London.

${ }^{\dagger}$ Centre for European Economic Research, Mannheim, P.O. Box 1034 43, D-68034 Mannheim, Germany; ullrich@zew.de. The author is currently also a scholar at the "WIN-Kolleg" of the Heidelberg Academy of Sciences.

${ }^{\ddagger}$ For useful feedback, we thank the audience at the Macro Brown Bag Workshop at Reading, 20 February 2007, the 24th GdRE International Symposium on Money, Banking and Finance in Rennes, 14-15 June 2007, and in particular Oliver Grimm, Eric Mayer and our discussant Blandine Zimmer. All remaining errors are the responsibility of the authors. 


\section{Non-technical Summary}

Whereas the independence of monetary and, to a lesser extent, fiscal policy has received considerable attention, the implications of complementing it with democratic accountability of the corresponding autonomous policymaking institutions has not been much studied. In an optimization-based theoretical model, we analyze the effects of such accountability in the form of possible overriding by the government of economic policy decisions delegated to two committees of experts with mandates in the monetary and fiscal areas, respectively. Because accountability is only reasonable if the institution to be made responsible is sufficiently autonomous in the first place, we allow for different degrees of independence and interaction of the appointed committees, each taken in its entirety as a policymaking unit or agent, and the elected government, as principal.

The equilibrium outcomes of these alternative institution-design frameworks are then compared and ranked according to key macroeconomic performance criteria such as inflation expectations, inflation, output and the budget deficit. Our results stress the trade-off between anchoring inflation expectations on target and output stabilization that is not solved with accountability. What we can conclude is that if the priority is to manage inflation and inflation expectations, a society should opt for independent monetary policy which is not constrained by the threat of its decisions being overridden, no matter whether fiscal policy is similarly independent or fully dependent. If, on the other hand, a society would prefer to mitigate the fluctuations of output and employment, policy-

making by expert committees should be additionally constrained either by accountability mechanisms such as override clauses or similar in effects or by permitting instrument but not goal independence as, for instance, in popular inflation targeting regimes of monetary policy. 


\section{Contents}

1 Motivation 1

2 The Basic Model $\quad 4$

2.1 The Target System and Sharing of Power . . . . . . . . . . . . . . . 4

2.2 The Monetary Authority . . . . . . . . . . . . . . . . 5

2.3 The Fiscal Authority . . . . . . . . . . . . . . . . . . . . . . . 6

2.4 The Economy and the Conduct of Macroeconomic Policy . . . . . . . . . 7

3 Key Results 9

3.1 Delegation of Economic Policy without Accountability . . . . . . . . . . 10

3.2 Delegation of Economic Policy with Accountability . . . . . . . . . . . . 11

3.3 Ranking of Regimes by Expected Inflation Outcomes . . . . . . . . . . . 13

3.4 Ranking of Regimes by Actual Inflation Outcomes . . . . . . . . . . . . . 17

3.5 Ranking of Regimes by Actual Output Outcomes . . . . . . . . . . . . . 19

3.6 Ranking of Regimes by Actual Deficit Outcomes . . . . . . . . . . . . . 23

4 Concluding Remarks $\quad 25$

$\begin{array}{ll}\text { A Model Solution } & 27\end{array}$

B Summary Tables $\quad 31$

\section{List of Figures}

1 Effects of policy decisions on output under accountability . . . . . . . . 22

\section{List of Tables}

1 Overview of the different policy regimes . . . . . . . . . . . . . 31

2 Ranking of expected and actual inflation outcomes across policy regimes 31

3 Ranking of output outcomes across policy regimes . . . . . . . . . . . . . 32

4 Ranking of deficit outcomes across policy regimes . . . . . . . . . . . . 32 


\section{Motivation}

The purpose of this paper is to address a central question in institution design with direct implications for policymaking: How are different degrees of independence of monetary and fiscal policies affected in influencing macroeconomic outcomes when complemented with accountability? A particular novelty of our approach is that, following proposals notably by Wyplosz (2005), we set to explore alternative social arrangements that delegate to independent but accountable non-elected expert committees both monetary and fiscal policy implementation. Such institutional mechanisms are theoretically appealing because of their potential to enhance policy credibility and effectiveness compared to the situation where elected fiscal authorities and governments induce the well-known problems of dynamic inconsistency, inflationary bias and political business cycles. More precisely, in a way symmetric to an appointed independent but accountable Monetary Policy Committee (MPC) implementing a mandate delegated by law, we incorporate an analogous independent but accountable Fiscal Policy Committee (FPC), with a corresponding mandate in the fiscal policy area.

Our set-up builds upon the existing literature, both traditional, and mostly ad-hoc, and modern, and partly microfounded. There are two instruments at disposal, the interest rate to conduct monetary policy and the consolidated government budget deficit to conduct fiscal policy. Each implementing authority is assigned or chooses a target, and actions are potentially, but not necessarily, coordinated. There are three goals to achieve at a social level, an output, an inflation and a public deficit target. We then consider alternative institutional frameworks for macroeconomic policymaking, spanning different degrees of independence without or with accountability modeled as an override clause which the government may implement or not. Independence and accountability are, thus, both defined with respect to the government. ${ }^{1}$ The government, being the principal, grants independence to the fiscal and/or monetary authority. These institutions, as agents, are accountable within their mandate for the degree of freedom each of them is allowed in conducting the respective policies. Our conceptual and modeling approach builds upon some related work, most directly on Lohmann (1992), Dixit and Lambertini (2003), Demertzis, Hughes Hallet and Viegi (2004), Wyplosz (2005), Castellani and Debrun (2005), Mihov and Sibert (2006), Hughes Hallet and Libich (2006), Mihailov (2006) and Ullrich (2007).

The huge theoretical and empirical literature on optimal monetary policy has generally established that a more autonomous central bank tends to lead to a lower actual inflation, on average. However, there have also been claims against too much central bank independence, e.g., for reasons of unaccountability that is not acceptable in a democracy. Fischer (1994) and Debelle and Fischer (1994) have first argued that instrument independence coupled with goal dependence - specified by Svensson (1997) and Herrendorf (1998) as an inflation targeting framework, whereby the government delegates the refer-

\footnotetext{
${ }^{1}$ Which we would identify throughout with the parliament and society.
} 
ence interest-rate setting to the central bank or an MPC but retains the quantification of the numerical inflation goal for itself - is the socially optimal institutional arrangement to formulate and implement monetary policy in a democratic society. This type of monetary regime has been eloquently qualified by Bernanke and Mishkin (1997) as "constrained discretion", again in an inflation targeting context. Eijffinger and Hoeberichts (2002) have further emphasized that such a democratic approach to the conduct of monetary policy would require augmented responsibility of the central bank for its actions as well as accountability to the government and/or to the parliament. An essential dimension of accountability is transparency, in the sense that it is a necessary precondition for any form of a wider, non-secretive accountability to be effectively implemented. Accountability preconditioned by transparency also has the potential to solve the private information problem identified by Canzoneri (1985) when central bank discretion is optimal.

As far as optimal fiscal policy is concerned, few clear and general results seem to be supported theoretically or empirically on a broad basis, no matter that a number of institutional regulations stipulate certain restrictions on fiscal discretion, e.g., the Maastricht Treaty and the Stability and Growth Pact in the EMU or the "golden rule" in the UK. As in monetary policy, the trade-off between value judgement and specialized knowledge plays a crucial role in delegating fiscal policy to an independent institution (Calmfors 2003). If the effects of fiscal policy affect the whole society and expertise plays a crucial role, fiscal policy can be delegated because democratic accountability is not the main objective (Blinder 1997, 121). Fiscal policy as stabilization policy is characterized by technical knowledge, not so much by judgment as, e.g., redistribution (Calmfors 2003, 334). Therefore, stabilization can be delegated, whereas all other areas such as redistribution and provision of public goods should not be delegated. However, the separation of these tasks is not as easy as theoretical models might suggests because fiscal policy touches the core of the political decision process (Buti, Eijffinger, and Franco 2003, 15).

With respect to both monetary and fiscal policy considered jointly in their interdependence, major earlier work follows the optimization-based Ramsey (1927) approach ${ }^{2}$ or relates to the fiscal theory of the price level. ${ }^{3}$ Another strand derives from the gametheoretic literature on strategic interaction, policy conflict, coordination failures and the need for coordinated actions if policy effectiveness is to be increased, e.g., in Nordhaus (1994). It then extends into the more recent research on the design of optimal incentive schemes, which could be thought of as contracts or institutions. Separation and delegation of powers from a principal to an agent and the related incentive-compatibility design and enforceability with view to some social optimum have been the key issues of focus in that strand, and we here contribute further in this particular direction.

Whereas independence has received much attention in the academic literature, accountability is a concept that is not yet clearly defined, especially in theoretical work.

\footnotetext{
${ }^{2}$ E.g., Lucas and Stokey (1983), Chari and Kehoe (1999), Benigno and Woodford (2003), SchmittGrohé and Uribe (2004 a, b).

${ }^{3}$ Notably, with Ricardian equivalence, McCallum and Nelson (2006) have claimed that monetary-fiscal coordination does not matter at all.
} 
Following essentially Lohmann (1992), we model accountability as an override clause where the government is able to change committee decisions according to its preferences following large shocks; yet in normal times, a conservative central banker conducts monetary policy according to her own preferences. Other approaches to incorporate accountability into a formal set-up certainly exist. Briault et al. (1997) analyze the literature on central bank independence with regard to its implications for accountability. In Walsh (2003), accountability bears a close relationship to independence. Accountability arises if "the central bank is subject to pressures attributed to exogenous variation in political support for greater economic expansion" (Walsh 2003). Another possibility to explicitly model accountability is to equate accountability with cooperation (Demertzis, HughesHallet, and Viegi 1998). Castellani (2002) investigates accountability that is also modeled as ex post political intervention. Hughes Hallet and Libich (2006) define accountability in an encompassing way, as the final responsibility of monetary policy, and emphasize goal independence. Accountability is introduced as the punishability of the central banker following deviations of inflation from target. This modeling is in line with a linear contract, as in Svensson (1997).

Our major findings complement and extend the earlier literature. We compare the equilibrium outcomes of alternative policy frameworks and rank them according to key macroeconomic performance criteria such as inflation expectations, inflation, output and the budget deficit. Our results stress the trade-off between anchoring inflation expectations on target and output stabilization that is not moderated with accountability. We conclude that if the priority is to manage inflation and inflation expectations, a society should opt for independent monetary policy which is not constrained by the threat of its decisions being overridden, no matter whether fiscal policy is similarly independent. If, on the other hand, a society would prefer to mitigate the fluctuations of output and employment, policymaking by expert committees should be additionally constrained either by accountability mechanisms such as override clauses or similar in effects or by some form of constrained discretion limiting independence such as goal dependence.

The paper is organized as follows. The next section specifies our basic model, defining precisely the notions of independence and accountability, the alternative mandates of the institutions responsible for macroeconomic management, and the economic environment. Section 3 discusses our main results, first without accountability and then with accountability. Concluding remarks are offered in section 4. Finally, Appendix A presents the solutions of our model which arise from the optimization of the relevant authorities under the various policy regimes considered, and Appendix B collects summary tables of these regimes and their rankings across the key variables of interest. 


\section{The Basic Model}

We set up a model of the relationships among a principal, the Government (denoted by a $G$-superscript), and its two agents, the MPC ( $M$-superscript) and the FPC $(F$ superscript). ${ }^{4}$ The objective functions of the expert committees reflect independence and accountability issues. Independence is granted with regard to the degree the monetary or fiscal authority can set its own targets and follow its own preferences. Alternative institution-design regimes between the extremes of complete freedom of action and full dependence of both authorities are also theoretically formulated along these lines. Accountability is modeled as the possibility of overriding committee decisions that would imply costs for the Government specific to each regime and, thus, prevent frequent overriding.

\subsection{The Target System and Sharing of Power}

Assuming additive separability of a quadratic loss function for each player, rational expectations and perfect information, our benchmark is the case of joint optimization with regard to the three objectives, output, inflation, and the public-sector budget deficit, conducted by the Government. Its loss function is written as: ${ }^{5}$

$$
L^{G}=\frac{\gamma_{y}^{G}}{2}\left(y-y^{*, G}\right)^{2}+\frac{\gamma_{\pi}^{G}}{2}\left(\pi-\pi^{*, G}\right)^{2}+\frac{\gamma_{d}^{G}}{2}\left(d-d^{*, G}\right)^{2},
$$

where $y$ is the realized output level, $\pi$ denotes the inflation rate, and $d$ is some measure of the government budget deficit; $\gamma_{j}^{G}$, for $j=y, \pi, d$, are the preference "weights" and an asterisk denotes target levels of the respective variables.

By contrast, we assume that with separation of powers our three players are assigned different prerogatives and minimize the following institution-specific loss functions. The elected Government, being representative of the public, minimizes (1) again. But the difference now is a (constant) cost term made explicit further down and capturing the fact that the Government would only be able to determine economic policy if it overrides committee decisions. This overriding as a form of accountability comes at some cost because delegation of economic policy to an independent agency has been made in the first place. Overriding committee decisions would call for a public procedure that results in costs for the Government because it deviates from its initial delegation decision. ${ }^{6}$ Whereas the preferences of the MPC and the FPC constitute the reference for determining the advantage of delegating monetary and fiscal policy to the appointed experts, the

\footnotetext{
${ }^{4}$ Each of these three policymaking units is considered as a whole, i.e., in its entirety. We, thus, do not address here aspects of structure and configuration of decision power: neither within the committees, as much of the literature on MPCs has done, nor within the Government.

${ }^{5}$ The usual discount factor parameter $\beta$ in dynamic models is eliminated from further consideration in our static framework, as in most of the related literature.

${ }^{6}$ We assume that accountability always requires, hence, always implies transparency. Therefore, and without loss of generality, we fix the degree of transparency to be full, or - which is an alternative interpretation - any constant amount necessary to implement efficient monitoring and, thus, enforce accountability.
} 
Government delivers the reference point for dependent policymaking in accordance with the literature. Moreover, the Government is the ultimate institution to hold the MPC and the FPC accountable in our model.

For the monetary authority, the MPC, we assume a quadratic loss function that is standard in the literature:

$$
L^{M}=\frac{\gamma_{\pi}^{M}}{2}\left(\pi-\pi^{*, M}\right)^{2}+\frac{\gamma_{y}^{M}}{2}\left(y-y^{*, M}\right)^{2}
$$

Finally, for the fiscal authority, the FPC, we have in a symmetric fashion:

$$
L^{F}=\frac{\gamma_{d}^{F}}{2}\left(d-d^{*, F}\right)^{2}+\frac{\gamma_{y}^{F}}{2}\left(y-y^{*, F}\right)^{2}
$$

We assume that the primary goal for the MPC is to keep inflation on target. Output stabilization also plays some role but receives a lower weight in the loss function. The deficit is not a concern for monetary policy. Therefore we have $\gamma_{\pi}^{M}>\gamma_{y}^{M}$. In a similar way, the FPC is mostly concerned with having the deficit on target, $\gamma_{d}^{F}>\gamma_{y}^{F}$; it also cares about output, but not about inflation. Naturally, the committees give a higher absolute and relative weight to their primary goal compared to the Government:

$$
\gamma_{\pi}^{M}>\gamma_{\pi}^{G}, \quad \frac{\gamma_{\pi}^{M}}{\gamma_{y}^{M}}>\frac{\gamma_{\pi}^{G}}{\gamma_{y}^{G}} \quad \text { and } \quad \gamma_{d}^{F}>\gamma_{d}^{G}, \quad \frac{\gamma_{d}^{F}}{\gamma_{y}^{F}}>\frac{\gamma_{d}^{G}}{\gamma_{y}^{G}}
$$

To derive our theoretical results, we further assume that the MPC and the FPC, being non-elected policy institutions consisting of experts, do not have an overambitious output target. Rather, they pursue a policy that brings output to its "normal" (or "natural") level, $y^{*, M}=y^{*, F}=y^{N}$. We then denote $\pi^{*, M}=\pi^{*}$ and $d^{*, F}=d^{*}$ to simplify notation. However, the Government has an output target that is higher than the normal level, reflecting what we would call a "re-election concern", $y^{*, G}>y^{N}$. This translates into the inflation and budget deficit targets too, $\pi^{*, G}>\pi^{*}$ and $d^{*, G}>d^{*} .^{7}$

\subsection{The Monetary Authority}

The MPC is independent if it can conduct monetary policy free of constraints and influence from the government, parliament or interest groups (see, e.g., de Haan and Eijffinger 2000). To operationalize independence into a theoretical model, we follow the mainstream (New Keynesian or Neo-Wicksellian) monetary policy literature in assuming that the MPC optimizes an objective function with respect to the interest rate. Under partial independence, it is forced to take the preferences and the objectives of the Government into account, because independence is granted from the Government. This is modeled by

\footnotetext{
7 "Coordination" only arises in two senses in our model: (i) if the government is in charge of fiscal and monetary policy; (ii) insofar the targets of the two committees are assumed the same while their preference weights differ, which appears more realistic given the fact that monetary and fiscal authorities communicate and coordinate at an expert level frequently enough. In all other cases, the policies are not coordinated.
} 
a weighting, $0 \leq \theta^{M} \leq 1$, between the objective functions of the MPC and the Government. Such a formulation allows to capture various degrees of instrument (in)dependence in addition to goal (in)dependence, and is written into the MPC's objective function as:

$$
Z^{M}=\theta^{M} L^{G}+\left(1-\theta^{M}\right) L^{M}
$$

If $\theta^{M}=0$, the MPC is granted complete (instrument and goal) independence, because it can determine the interest rate according to its own objective function, that is, without taking the preferences and targets of the Government into account. If $\theta^{M}=1$, the MPC is instrument- as well as goal-dependent, i.e., operating with no discretion at all and, effectively, suppressed as institution.

Accountability of the expert committees requires that each of them is responsible for the process and the results of its policy and is able to explain its actions. In the following analysis accountability is justified from a democratic point of view and not because of economic necessity. Accountability also includes mechanisms to sanction the behavior of the committees. As mentioned, democratic accountability can take on many different forms. For simplicity, we adopt the modeling shortcut in Lohmann (1992) and restrict our analysis to an ex post overriding of committee decisions by the Government. In case of overriding MPC's decision, the Government would step in and put through its preferred inflation rate by setting the nominal interest rate at the required level. Therefore, we can write accountability as:

$$
\begin{aligned}
W^{M} & =\alpha\left(L^{G}+C^{M}\right)+(1-\alpha) Z^{M} \\
& =\left[\theta^{M}+\left(1-\theta^{M}\right) \alpha\right] L^{G}+(1-\alpha)\left(1-\theta^{M}\right) L^{M}+\alpha C^{M},
\end{aligned}
$$

where $\alpha=1$ if the MPC is overridden and cannot implement its desired inflation rate. In this case, the Government holds the monetary committee accountable and decides about inflation. The Government's preferences and targets receive a weight in the objective function that is higher than in the case of independent but unaccountable monetary committee summarized by equation (4). If the MPC is overridden and forced to implement the inflation rate preferred by the Government, the latter would incur a $\operatorname{cost} C^{M}$. With $\alpha=0$, the MPC can implement its preferred inflation rate and will not be held accountable by having its decisions overridden.

\subsection{The Fiscal Authority}

Whereas independence of monetary policy from government influence is well established, the idea of fiscal policy independence is not equally developed in the literature. This is not least because of the distributive effects fiscal policy exerts. These effects call for ex ante democratic control. However, as Wyplosz (2005) argues, the determination of the fiscal deficit can be delegated to an independent agency, since it does not differ much in its distributive effects from the determination of the interest rate by monetary policy. 
Following this argumentation, we assume a framework where fiscal policy can be delegated to an expert committee in the same way as monetary policy. Therefore, the objective function of the FPC resembles that of the MPC, and the degree of independence is again captured by a weighting, $0 \leq \theta^{F} \leq 1$, between the objective function of the Government and that of the FPC:

$$
Z^{F}=\theta^{F} L^{G}+\left(1-\theta^{F}\right) L^{F}
$$

where $\theta^{F}=0$ results in complete (instrument and goal) independence of the FPC, while $\theta^{F}=1$ yields the opposite extreme with a completely dependent fiscal policy. As with the MPC, the FPC is held accountable by the Government. If the fiscal committee sets the deficit in a way that its actual value deviates to a large extent from the deficit preferred by the Government, the latter will step in and override the decision of the FPC. By analogy with the implementation of monetary policy, we then have

$$
\begin{aligned}
W^{F} & =\alpha\left(L^{G}+C^{F}\right)+(1-\alpha) Z^{F} \\
& =\left[\theta^{F}+\left(1-\theta^{F}\right) \alpha\right] L^{G}+(1-\alpha)\left(1-\theta^{F}\right) L^{F}+\alpha C^{F},
\end{aligned}
$$

where $\alpha=0$ if the expert committee conducts fiscal policy, and $\alpha=1$ if the Government overrides FPC's decision and determines a deficit level according to its own preferences.

\subsection{The Economy and the Conduct of Macroeconomic Policy}

The economy can be described by an aggregate demand and an aggregate supply function in a standard way. ${ }^{8}$ Demand depends on the real interest rate that is determined by the nominal interest rate, $i$, the instrument of monetary policy, and the instrument of fiscal policy, the deficit $d$. The expected value of the demand shock, $\epsilon$, is zero. Supply deviates from the "normal" output level, $y^{N}$, if inflation, $\pi$, and inflation expectations, $\pi^{e}$, do not match. Again, the expected value of the supply shock, $\varepsilon$, is zero. Imposing equilibrium of demand and supply determines the output level:

$$
\begin{aligned}
y^{D} & =a d-b\left(i-\pi^{e}\right)+\epsilon, \\
y^{S} & =y^{N}+c\left(\pi-\pi^{e}\right)+\varepsilon, \\
y & \equiv y^{D}=y^{S}
\end{aligned}
$$

with $a>0, b>0, c>0$ all positive coefficients which could be, themselves, further defined in terms of underlying deeper parameters that have parallels to the New Keynesian or Neo-Wicksellian microfounded model for monetary policy analysis, with $y^{N}$ the flexibleprice level of output (see, e.g., Woodford, 2003).

We assume that, similarly to Lohmann (1992) and Mihov and Sibert (2006), overriding would occur in case of large supply shocks. More importantly, following Lohmann (1992) and Hughes Hallet and Libich (2006), among others, the MPC and the FPC in our set-

\footnotetext{
${ }^{8}$ Reminiscent of Sargent and Wallace (1975) and the huge literature they generated.
} 
up take into account the possibility of their decisions being overridden when optimizing their behavior only via inflation expectations. We model the Government's incentives to override endogenously, along the following lines. As explained, the Government can determine the inflation rate, the output gap and the deficit according to its targets and preferences by minimizing its own loss function. Any deviation of the instruments from the corresponding optimal levels will result in a deviation from the desired minimal loss, regardless whether this deviation is positive or negative because of the quadratic form. The levels of the variables that are determined by the committees will result in a higher loss in any case since the monetary and fiscal policymakers optimize each according to its own loss function. Therefore, the Government would override the committee decisions in every event if there are no costs to do so. If there are costs of overriding, the gain of doing so and choosing the variables according to the Government's own loss function compared to the loss realized in case of committee decisions has to be higher than the costs:

$$
L^{G}\left(y^{c o m}, \pi^{c o m}, d^{c o m}\right)-L^{G}\left(y^{G}, \pi^{G}, d^{G}\right)>C^{M}+C^{F}>0 .
$$

Note that each of the arguments in the two loss functions above is endogenous and depends further on the materialized cost push shock $\varepsilon$, given the probability $\alpha$ implied ex ante for the occurrence of overriding ex post in any particular institution-design framework with accountability. We could have written that as $j=j(\varepsilon ; \alpha)$ for $j=y, \pi, d$ under the two possibilities captured by the superscripts com (no overriding) and $G$ (overriding) in (9), which we do not do to keep the notation less complicated. Since among the deeper determinants of the endogenous arguments of the above loss functions are also the various target values, in addition to $\varepsilon$ and $\alpha$, and since these constant targets are not subject to optimization ex post, as assumed, the only magnitude that changes in every state of nature and influences the relative loss in (9) is the supply shock $\varepsilon$. The larger its positive or negative realization, the larger the deviation of the macroeconomic variables determined via the respective instruments by the committees from the level the Government would have chosen. There would, thus, be a threshold of the supply shock $|\bar{\varepsilon}|$ where it equates the loss of the Government, $L^{G}\left(y^{G}, \pi^{G}, d^{G}\right)$, including the costs of overriding, $C^{M}+C^{F}$, and the loss of the Government conditioned on the decisions of the committees, $L^{G}\left(y^{c o m}, \pi^{c o m}, d^{c o m}\right)$. Any larger shock would lead to a net gain of the Government when overriding. The probability that such a large supply shock occurs is given by $\alpha$ and known to the agents when forming their inflation expectations. With probability $1-\alpha$ the supply shock is not large enough to cross the threshold for overriding. This can be written as

$$
L^{G}\left(y^{c o m}, \pi^{c o m}, d^{c o m}\right)-L^{G}\left(y^{G}, \pi^{G}, d^{G}\right)\left\{\begin{array}{l}
>C^{M}+C^{F}, \quad|\varepsilon|>|\bar{\varepsilon}| \quad \text { with prob } \alpha \\
\leq C^{M}+C^{F}, \quad|\varepsilon| \leq|\bar{\varepsilon}| \text { with prob } 1-\alpha
\end{array} .\right.
$$

To put it differently, the Government would determine the inflation rate via the interest rate and the deficit with probability $\alpha$. With probability $1-\alpha$, the committees decide 
about the appropriate level of their respective instruments and ultimately determine the inflation rate. Private agents will take this institutional mechanism (captured in our model by the value of the accountability parameter $\alpha$ ) into account, understanding that the level of macroeconomic variables such as inflation and output can be determined ex post either by the MPC and the FPC or by the Government, and will form inflation expectations accordingly. Inflation expectations are, consequently, a weighted average of the inflation rate resulting in circumstances where the Government ultimately decides (weighted with probability $\alpha$ ) and the inflation rate in cases where the committees conduct monetary and fiscal policy (weighted with probability $1-\alpha$ ). The probability of overriding and the formation of inflation expectations are exogenously given and cannot be influenced by policymakers. ${ }^{9}$

The order of events is assumed to be as follows. The form of accountability, in our model the possibility of overriding, is determined by law or by the Government and goal and/or instrument independence is granted to the MPC and the FPC. If there is goal independence, each institution chooses its target, the inflation rate and the budget deficit, respectively. ${ }^{10}$ Then, the private sector forms rational expectations about the inflation rate assuming a linear rule for the interest rate and the budget deficit. The supply and demand shocks are realized and observed by the policymakers. The MPC and the FPC set the interest rate and the budget deficit, respectively, resulting from their optimization. The Government checks whether any overriding, as part of the accountability mechanism, has to take place. Inflation, output and the budget deficit are realized.

\section{Key Results}

The results from solving our model we characterize in the present section concern inflation expectations and the actual levels of inflation, output and the budget deficit depending on target values and shocks. ${ }^{11}$ We consider different policy regimes according to the degree of independence and accountability of the committees (see Table 1 for a listing of the possibilities).

\section{[ Table 1 about here ]}

To optimally set the instrument levels, i.e., the interest rate and the budget deficit, the loss function of the respective policymaker is minimized with respect to the instrument at hand. The Government can use the interest rate and the deficit jointly whereas the MPC determines the interest rate taking the deficit as given and the FPC minimizes its loss via the deficit taking the interest rate as given. It is assumed that any of the expert committees, when independent, and the Government optimize simultaneously and

\footnotetext{
${ }^{9}$ Future extensions to less restrictive environments are, of course, contemplated on this aspect.

${ }^{10}$ We do not model the choice of an optimal target level.

${ }^{11}$ The interest-rate rules, as the interest rate is not itself a target variable but only an instrument in our set-up, are not presented here. They are available upon request.
} 
ex post, i.e., under perfect information. ${ }^{12}$ Moreover, agents form inflation expectations by assuming that the instrument rules are linear ${ }^{13}$ in the different target values of the relevant macroeconomic variables, that is, inflation, output and the deficit, and the exogenous shocks.

The precise solutions by policy regime and respective variable are provided in Appendix A. The results show, overall, that the different equilibrium values have a similar structure depending on (a "weighted average" of) target values, gaps between the corresponding inflation and output targets of the different decision-makers, the normal output level and the exogenous shocks. The above key terms are "weighted" by expressions that depend on the parameters of the economy and the preference structure, $\gamma$, of the policymakers. These preference "weights" play an important role, as they characterize the different possibilities for combining the preferences of the Government, the MPC and the FPC according to the degree of independence $\left(0 \leq \theta^{M} \leq 1\right.$ and $\left.0 \leq \theta^{F} \leq 1\right)$ and accountability $(0 \leq \alpha \leq 1)$ of the committees. For weighting the preferences of the Government and the FPC regarding achievement of the deficit target and the output target, the degree of fiscal independence $\left(\theta^{F}\right)$ matters. For weighting the preferences of the Government and the MPC with regard to the targets on inflation and output, the degree of monetary independence $\left(\theta^{M}\right)$ matters.

\subsection{Delegation of Economic Policy without Accountability}

Without accountability $(\alpha=0)$, the MPC and the FPC can minimize their respective loss, equations (4) and (6), given the strategy of the other committee. Therefore, they have to take into account the preferences of the Government to an extent that depends only on the degree of independence.

In the solution to the general case of the optimization of the MPC's and the FPC's loss functions with partial degree of independence, Regime A (Partial Independence without Accountability), inflation and inflation expectations differ only because of the supply shock. The demand shock is completely offset by monetary policy. Because the committees and the Government support different target values of inflation, output and the deficit, and monetary and fiscal policy are not necessarily completely independent, Government preferences matter and the gaps between the targets influence the different variables.

There are four interesting limiting cases that arise in a set-up without accountability. These are a completely (in)dependent monetary and fiscal policy as well as a completely independent monetary (fiscal) and completely dependent fiscal (monetary) policy.

If monetary and fiscal policy are completely dependent, $\theta^{M}=1$ and $\theta^{F}=1$, it is as if the Government determines economic policy according to its own liking. The committees

\footnotetext{
${ }^{12}$ The more complicated cases of sequential optimization and/or imperfect information are left for future research.

${ }^{13}$ All policy feedback rules are restricted to be linear here. Nonlinear reaction functions are a next natural extension.
} 
only implement the instrument values that the Government decides. This Regime A1 (Government Optimization without Accountability) is therefore, in essence, Government optimization. The results show that, whereas the deficit is on target, the inflation rate and inflation expectations end up above target because of the inflationary bias that originates in targeting output above its natural level, i.e., in the Government's re-election concern. Actual inflation and inflation expectations differ because of the supply shock that is not completely offset by policymakers. This yields an output level that deviates from its natural level; upwards if a positive supply shock has materialized, and downwards in the case of a negative supply shock.

The second limiting case is that of completely independent monetary and fiscal policies, $\theta^{M}=0$ and $\theta^{F}=0$. In this Regime A2 (Independent and Unaccountable Committees), both committees are independent from the Government to determine the respective instrument level and are not accountable, in the sense that their decisions cannot be changed. In this case, the deficit reacts to the supply shock and differs from target value. Inflation expectations are on target and differ from inflation because of a not fully dampened supply shock. This leads also to an output level that deviates from the normal one in the direction of the cost-push shock.

In Regime A3 (Independent and Unaccountable MPC with Completely Dependent FPC), monetary policy is assumed to be completely independent and unaccountable, whereas the FPC is completely dependent, $\theta^{M}=0$ and $\theta^{F}=1$. Because fiscal policy is conducted with regard to Government preferences and targets, the deficit explicitly depends on the gaps between the output and inflation targets, where the basic level of the deficit is given by the Government target. Inflation expectations are anchored at target value and differ from the inflation rate because of the supply shock. This leads to an output level different from the normal level, depending on the sign and size of the supply shock.

If monetary policy is completely dependent on the Government but fiscal policy is completely independent, $\theta^{M}=1$ and $\theta^{F}=0$, we have Regime A4 (Independent and Unaccountable FPC with Completely Dependent MPC). Again, there is the influence of the difference between targets and the not completely offset supply shock, leading to deviations of output from target via the gap between inflation and inflation expectations.

\subsection{Delegation of Economic Policy with Accountability}

With accountability modeled explicitly $(0<\alpha \leq 1)$, there are two possible deficit levels, interest rates, inflation rates and output levels depending on whether overriding takes place or not. If no overriding occurs, the monetary and fiscal policy committees (hence, superscript com in the relevant subsections of Appendix A) are left to determine simultaneously the inflation rate and the output level. If overriding occurs, the Government (superscript $G$ ) steps in and ultimately determines instead the level of the macroeconomic variables. There is only one level of inflation expectations, however, giving each of the two possibilities for ex post inflation a probability of $\alpha$, respectively $1-\alpha$. In contrast 
to the preceding subsection, Government preferences matter in every regime because the committees can now be overridden even in cases of complete independence, a possibility that is taken account of in the formation of inflation expectations.

The general solution in equilibrium for Regime B (Partial Independence with Accountability) yields the deficit, inflation expectations, inflation and output if the Government steps in and decides about the instruments or if the MPC and the FPC are not overridden and conduct policy according to their preferences. In both cases, inflation expectations are the same because agents do not know ex ante the size of the supply shock that causes the Government to override MPC's and FPC's decisions ex post. Therefore, agents take both possibilities into account when forming inflation expectations. However, the policymakers optimize ex post, simultaneously and under perfect information, knowing the size of the supply shock, so inflation, output and the deficit are decided among the authorities in charge.

Again, we consider the same four special cases. If both committees are completely dependent, $\theta^{M}=1$ and $\theta^{F}=1$, we have Regime B1 (Government Optimization with Accountability). The results are the same as if the Government would minimize the loss from start, i.e., as in Regime A1. With complete dependence, the committees only implement the instruments that are determined according to the Government's preferences and targets.

Regime B2 (Independent but Accountable Committees) is characterized by completely independent but accountable committees, $\theta^{M}=0, \theta^{F}=0,0<\alpha \leq 1$. The structure of the results is the same as if with partially independent committees. However, the influence of the Government is muted because it affects the results only according to the inflation expectations of private agents, and not from the very beginning via the objective functions of the committees as it would be the case with incomplete independence. In this regime, the difference between the variables determined when the Government or the committees ultimately decide should be larger than under incomplete independence.

If there is an independent but accountable MPC only and fiscal policy is completely dependent on the Government, $\theta^{M}=0,0<\alpha \leq 1$ and $\theta^{F}=1$, we are in Regime B3 (Independent but Accountable MPC with Completely Dependent FPC). The deficit, the inflation rate, inflation expectations and output are the same as in Regime B2. What matters is the dependence of monetary policy whereas the (in)dependence of fiscal policy does not play a role for the determination of inflation, inflation expectations and output. Only the deficit will be determined by the preferences of the FPC if the committees are left to decide.

An independent but accountable FPC only, $\theta^{F}=0,0<\alpha \leq 1$ and $\theta^{M}=1$, Regime B4 (Independent but Accountable FPC with Completely Dependent MPC), yields the same results as Regime A4 if the FPC is left to decide. If the Government overrides instead, it will implement $d^{G}=d^{*, G}$, but inflation, inflation expectations and output would be the same as if the committees would determine the instrument levels. The 
particular institutional arrangement being A4 or B4 is, thus, not crucial for the level of the macroeconomic variables except for the deficit.

\subsection{Ranking of Regimes by Expected Inflation Outcomes}

We now propose an interpretation of our key results along a few dimensions of ranking the equilibrium outcomes of our model. We discuss alternative rankings based on a single criterion, and focus on different criteria in turn, to highlight each of the three target variables. To them, we add a fourth criterion, inflation expectations, with which we start here the rankings. The reason is that anchoring private-sector expectations, although not a target in the explicit loss functions policymakers optimize upon, is perhaps the most important task of monetary and fiscal policy. With regard to the ranking of regimes according to inflation expectations, we come to the following conclusions.

Proposition 1 An institution-design regime that implements optimal macroeconomic policies with the lowest anchor for inflation expectations is one with a fully independent non-elected MPC whose decisions are explicitly guaranteed not to be overridden by, and in the latter sense unaccountable to, elected politicians.

Corollary 1.1 Provided that monetary policy is delegated to a fully independent and unaccountable $M P C$, delegation or not of fiscal policy to a similarly unaccountable and independent FPC does not matter for inflation expectations.

Corollary 1.2 All considered mechanisms for policymaking without accountability modeled as an override clause (Regimes A) dominate the corresponding mechanisms with accountability (Regimes B) along the dimension of anchoring inflation expectations.

\section{Proof of Proposition 1 and the related corollaries 1.1 and 1.2}

A. Without Accountability We start by selecting the special case(s) with the lowest inflation expectations outcome among the identified four regimes without accountability in our framework. We show below that Regimes A2 and A3 perform best along this particular dimension of ranking we here consider first. If the appointed MPC of experts is completely independent of any interference of the elected Government, in terms of being both allowed to pursue its own targets and spared from the possibility to be overridden, it will efficiently anchor down inflation expectations precisely at its target:

$$
\pi_{A 2, A 3}^{e}=\pi^{*}<\pi^{*, G}
$$

This is true no matter whether the FPC is also fully independent and unaccountable. 
We next compare with the above supposed minimum the expectations effect in the case of fully dependent monetary policy, with fiscal policy either fully dependent or delegated to an independent and unaccountable expert committee, i.e., Regimes A1 and A4.

$$
\pi_{A 1, A 4}^{e}=\pi^{*, G}+c \frac{\gamma_{y}^{G}}{\gamma_{\pi}^{G}}\left(y^{*, G}-y^{N}\right)
$$

Insofar we allow for any re-election concern of the Government, $y^{*, G}-y^{N}>0$, in line with the tradition of the literature on time-inconsistency, A1 and, identically, A4, produces a substantial inflationary bias, which is a standard result. The expected inflation is higher, i.e., the inflationary bias is stronger, the higher is the Government's weight on output relative to that on inflation, $\gamma_{y}^{G} / \gamma_{\pi}^{G}>1$, and the stronger is the reaction of aggregate supply to surprise inflation, captured by $c>0$. In fact, an elastic AS response to forecast errors in expectations, i.e., a steeper Phillips curve slope, $c>1$, magnifies the effect of any given measure, $y^{*, G}-y^{N}>0$, of the re-election concern on inflation expectations, while an inelastic AS response, i.e., a flatter Phillips curve slope, dampens it. ${ }^{14}$ Only if the Government is not pursuing an overambitious output target, $y^{*, G}-y^{N}=0$, inflation would be $\pi^{*}=\pi^{*, G}=\pi^{e}$, as in Regimes A2 and A3.

The special case of equally-split responsibility of policy formulation and implementation, $\theta^{M}=1 / 2$, then results in an intermediate magnitude of expected inflation:

$$
\pi^{e}=\frac{\gamma_{\pi}^{G}}{\gamma_{\pi}^{M}+\gamma_{\pi}^{G}} \pi^{*}+\frac{\gamma_{\pi}^{M}}{\gamma_{\pi}^{M}+\gamma_{\pi}^{G}} \pi^{*, G}+c \frac{\gamma_{y}^{G}}{\gamma_{\pi}^{M}+\gamma_{\pi}^{G}}\left(y^{*, G}-y^{N}\right) .
$$

Insofar the re-election concern exists, we still have an inflationary bias relative to the cases of fully independent MPC (A2 and A3). Yet now the expected inflation outcome is lower than the one under fully dependent monetary policy (A1 and A4), because of two reasons. First, the multiplier to the output target gap is now smaller relative to the latter two regimes, since $c \gamma_{y}^{G} /\left(\gamma_{\pi}^{M}+\gamma_{\pi}^{G}\right)<c \gamma_{y}^{G} / \gamma_{\pi}^{G}$, that is, because the preference weight of the equally-responsible monetary policymaker, $\gamma_{\pi}^{M}$, now plays a role in reducing the response of private-sector expectations to the re-election concern. Second, only a fraction, $0<\gamma_{\pi}^{M} /\left(\gamma_{\pi}^{M}+\gamma_{\pi}^{G}\right)<1$, of the overambitious Government's target for inflation, $\pi^{*, G}$, now forms the expected level of inflation, together with a smaller (assuming $0<\gamma_{\pi}^{G}<$ $\gamma_{\pi}^{M}<1$, as we do) fraction, $0<\gamma_{\pi}^{G} /\left(\gamma_{\pi}^{M}+\gamma_{\pi}^{G}\right)<1$, of the MPC's lower inflation target, $\pi^{*}$, consistent with attaining normal output level on average.

Finally, taking up the general case without accountability, Regime A,

$$
\pi_{A}^{e}=\frac{\left(1-\theta^{M}\right)}{\Pi} \gamma_{\pi}^{M} \pi^{*}+\frac{\theta^{M}}{\Pi}\left[\gamma_{\pi}^{G} \pi^{*, G}+c \gamma_{y}^{G}\left(y^{*, G}-y^{N}\right)\right]
$$

\footnotetext{
${ }^{14}$ There is no theoretical or empirical reason to restrict our parameter $c$ to a particular positive-valued range (Woodford 2003, p. 245). Earlier aggregative models have AS or Phillips curve relations where the analogous parameter to $c$ here is not restricted more than just being a positive number (Sargent and Wallace 1975, p. 242).
} 
it naturally splits into two regions. If we set $\theta^{M}=1 / 2$ in the general case above, so that $\Pi=1 /\left[2\left(\gamma_{\pi}^{G}+\gamma_{\pi}^{M}\right)\right]$ and, thus, becomes the average preference weight on inflation for the Government and the monetary committee, the above expression collapses exactly into the special case of equal responsibilities. Then (i) if $0<\theta^{M}<1 / 2$ so that the MPC opinion matters more than that of the Government in deciding on targets and preferences with respect to inflation (and output), $\pi^{*, G}$ and $y^{*, G}-y^{N}$ will be weighted less and $\pi^{*}$ more so that the re-election concern will be less important in expectation formation. Therefore, general case $\mathrm{A}$ (i) will be ranked between $\mathrm{A} 2=\mathrm{A} 3$ and the special case of $\theta^{M}=1 / 2$ in terms of our unique, expected inflation criterion of ranking institutional regimes here. By contrast, and following analogous reasoning, general case $\mathrm{A}$ (ii), where $1 / 2<\theta^{M}<1$, will come in this ranking between the special case of $\theta^{M}=1 / 2$ and $\mathrm{A} 1=\mathrm{A} 4$. The ranking we just derived is reflected in the top (Regimes A) half of the middle column of Table 2 further down.

B. With Accountability It is interesting first to note that consideration of accountability modeled as the explicit inclusion of an override clause in the incentive contracts written between the Government and the expert committees does not matter in terms of private-sector inflation expectations for the institution-design regimes where monetary policy is dependent: the expectation outcomes of Regimes B1 and B4 are exactly the same as the parallel outcomes of Regimes A1 and A4.

We thus turn to the two cases where the MPC is independent but now accountable, Regimes B2 and B3, in the sense of facing a possibility that its optimal decisions are overridden by the Government. Logically, this adds a constraint in the optimization of the MPC and influences it away from its priority on inflation expectations and more into stabilization considerations concerning actual inflation and output. This results in expectations formation that is less favorable than our best regimes on this account, A2 and A3:

$$
\begin{aligned}
\pi_{B 2, B 3}^{e}= & \frac{\alpha \gamma_{\pi}^{G}\left(\gamma_{\pi}^{M}+c^{2} \gamma_{y}^{M}\right)}{\alpha c^{2} \gamma_{\pi}^{G} \gamma_{y}^{M}+\gamma_{\pi}^{G} \gamma_{\pi}^{M}+(1-\alpha) c^{2} \gamma_{y}^{G} \gamma_{\pi}^{M}} \pi^{* G}+\frac{(1-\alpha) \gamma_{\pi}^{M}\left(\gamma_{\pi}^{G}+c^{2} \gamma_{y}^{G}\right)}{\alpha c^{2} \gamma_{\pi}^{G} \gamma_{y}^{M}+\gamma_{\pi}^{G} \gamma_{\pi}^{M}+(1-\alpha) c^{2} \gamma_{y}^{G} \gamma_{\pi}^{M}} \pi^{*} \\
& +\frac{c\left(\gamma_{\pi}^{G} \gamma_{y}^{M}(1-\alpha)+2 \gamma_{y}^{M}(1-\alpha) c^{2} \gamma_{y}^{G}+\gamma_{y}^{G}(1-\alpha) \gamma_{\pi}^{M}-c^{2} \gamma_{y}^{G} \gamma_{y}^{M}-\gamma_{y}^{G} \gamma_{\pi}^{M}\right)}{\alpha c^{2} \gamma_{\pi}^{G} \gamma_{y}^{M}+\gamma_{\pi}^{G} \gamma_{\pi}^{M}+(1-\alpha) c^{2} \gamma_{y}^{G} \gamma_{\pi}^{M}} y^{N} \\
& +\frac{\alpha c \gamma_{y}^{G}\left(\gamma_{\pi}^{M}+c^{2} \gamma_{y}^{M}\right)}{\alpha c^{2} \gamma_{\pi}^{G} \gamma_{y}^{M}+\gamma_{\pi}^{G} \gamma_{\pi}^{M}+(1-\alpha) c^{2} \gamma_{y}^{G} \gamma_{\pi}^{M}} y^{*, G}
\end{aligned}
$$

Take first "fair odds" of being overridden, i.e., $\alpha=1 / 2$. The general case of Regimes $\mathrm{B} 2=\mathrm{B} 3$ then translates into the following special case:

$$
\begin{aligned}
\pi_{B 2, B 3, \alpha=\frac{1}{2}}^{e}= & \frac{\left(\frac{1}{2} c^{2} \gamma_{\pi}^{G} \gamma_{y}^{M}+\frac{1}{2} \gamma_{\pi}^{G} \gamma_{\pi}^{M}\right)}{\left(\frac{1}{2} c^{2} \gamma_{\pi}^{G} \gamma_{y}^{M}+\frac{1}{2} \gamma_{\pi}^{G} \gamma_{\pi}^{M}\right)+\frac{1}{2} \gamma_{\pi}^{G} \gamma_{\pi}^{M}+c^{2} \gamma_{y}^{G} \gamma_{\pi}^{M}} \pi^{*, G}+\frac{\left(\frac{1}{2} \gamma_{\pi}^{G} \gamma_{\pi}^{M}+\frac{1}{2} c^{2} \gamma_{y}^{G} \gamma_{\pi}^{M}\right)}{\frac{1}{2} c^{2} \gamma_{\pi}^{G} \gamma_{y}^{M}+\frac{1}{2} \gamma_{\pi}^{G} \gamma_{\pi}^{M}+\left(\frac{1}{2} \gamma_{\pi}^{G} \gamma_{\pi}^{M}+\frac{1}{2} c^{2} \gamma_{y}^{G} \gamma_{\pi}^{M}\right)} \pi^{*} \\
& +\frac{\frac{1}{2} c\left(\gamma_{\pi}^{G} \gamma_{y}^{M}-\gamma_{y}^{G} \gamma_{\pi}^{M}\right)}{\frac{1}{2} c^{2}\left(\gamma_{\pi}^{G} \gamma_{y}^{M}+\gamma_{y}^{G} \gamma_{\pi}^{M}\right)+\gamma_{\pi}^{G} \gamma_{\pi}^{M}} y^{N}+\frac{\frac{1}{2} c^{3} \gamma_{y}^{M} \gamma_{y}^{G}+\left(\frac{1}{2} c \gamma_{y}^{G} \gamma_{\pi}^{M}\right)}{\frac{1}{2} c^{2} \gamma_{\pi}^{G} \gamma_{y}^{M}+\gamma_{\pi}^{G} \gamma_{\pi}^{M}+c\left(\frac{1}{2} c \gamma_{y}^{G} \gamma_{\pi}^{M}\right)} y^{*, G} .
\end{aligned}
$$


These coefficients have a common denominator and the following ranges of magnitude, respectively:

$$
\begin{aligned}
& 0<\text { Coeff. of } \pi_{B 2, B 3, \alpha=\frac{1}{2}}^{*, G}<1 ; \quad 0<\text { Coeff. of } \pi_{B 2, B 3, \alpha=\frac{1}{2}}^{*}<1 ; \\
& \text { Coeff. of } y_{B 2, B 3, \alpha=\frac{1}{2}}^{N}<0 \text { since } \gamma_{\pi}^{G} \gamma_{y}^{M}<\gamma_{y}^{G} \gamma_{\pi}^{M} ; \quad \text { Coeff. of } y_{B 2, B 3, \alpha=\frac{1}{2}}^{*, G}>0 .
\end{aligned}
$$

Comparing the coefficients above with the simple expression for the corresponding regimes without accountability, $\pi_{A 2, A 3}^{e}=\pi^{*}$, we can conclude that Regime A2=A3 dominates Regime $\mathrm{B} 2=\mathrm{B} 3$ for $\alpha=1 / 2$ in terms of anchoring inflation expectations to a lower level. First, the coefficients on $\pi^{*}$ and $\pi^{*, G}$ above are both between 0 and 1, implying some sort of weighting of the inflation targets of the MPC and the Government, with $\pi^{*}<\pi^{*, G}$, but with the coefficient on $\pi^{*, G}$ definitely smaller than that on $\pi^{*}$, since $\gamma_{\pi}^{G} \gamma_{y}^{M}<\gamma_{y}^{G} \gamma_{\pi}^{M}$ :

$$
\text { Coeff. of } \pi_{B 2, B 3, \alpha=\frac{1}{2}}^{*, G}<\text { Coeff. of } \pi_{B 2, B 3, \alpha=\frac{1}{2}}^{*} \text {. }
$$

Second, insofar $y^{*, G}>y^{N}$ and because the positive coefficient on the Government's output target dominates in absolute value the negative coefficient on the MPC's target of normal output, since $\gamma_{y}^{G} \gamma_{\pi}^{M}+c^{2} \gamma_{y}^{M} \gamma_{y}^{G}>\gamma_{y}^{G} \gamma_{\pi}^{M}-\gamma_{\pi}^{G} \gamma_{y}^{M}>0$,

$$
\mid \text { Coeff. of } y_{B 2, B 3, \alpha=\frac{1}{2}}^{*, G}|>| \text { Coeff. of } y_{B 2, B 3, \alpha=\frac{1}{2}}^{N} \mid \text {, }
$$

because another positive constant is added on top of the weighted inflation targets just discussed determining $\pi_{B 2, B 3, \alpha=1 / 2}^{e}$.

For the more general case of $0<\alpha<1 / 2$ (small(er) probability of overriding), the weight on the MPC's inflation target would be higher than in the special case of $\alpha=1 / 2$ relative to that of the Government's inflation target; and the weight on the Government's overambitious output target relative to normal output would be lower. Hence, on both counts, inflation expectations would be even lower than under $\alpha=1 / 2$. Conversely, for the more general case of $1 / 2<\alpha<1$ (high(er) probability of overriding), the weight on the MPC's inflation target would be lower than in the special case of $\alpha=1 / 2$ relative to that of the Government's inflation target; and the weight on the Government's overambitious output target relative to normal output would be higher. Hence, on both counts, inflation expectations would be higher than under $\alpha=1 / 2$.

Thus, being a "weighted average" of Government's and MPC's targets, not just for $\alpha=1 / 2$ but also for any general probability of overriding $0<\alpha<1$ as we showed above, expected inflation is higher with accountability in B2 and B3 than it is in the parallel cases with independent and unaccountable MPC in A2 and A3. Regime A2=A3 dominates Regime $\mathrm{B} 2=\mathrm{B} 3$ in terms of anchoring private-sector expectations. For the same reason and following analogous logic, Regime A dominates Regime B in terms of expectation formation. This completes our proof of Proposition 1 and corollaries 1.1 and 
The corresponding ranking of the above regimes along the inflation expectations dimension is summarized in the middle column of Table 2.

\subsection{Ranking of Regimes by Actual Inflation Outcomes}

Realized inflation differs from the rationally forecasted one only by a term containing the ex-post supply shock, $\varepsilon$ - as the demand shock, $\epsilon$, is accounted for by policy in every materialized state of nature - multiplied by some combination of parameters. Hence, all expressions that we analyzed in the preceding subsection are usable again with a slight modification. We present next the deviations $\pi-\pi^{e}$ across regimes and then rank the latter according to the smallest (in absolute value) deviation of actual from expected inflation.

Proposition 2 An institution-design regime that implements optimal macroeconomic policies with the lowest deviation of actual inflation from target is, again, one with a fully independent and unaccountable MPC of experts.

Corollary 2.1 Provided that monetary policy is delegated to a fully independent and unaccountable $M P C$, delegation or not of fiscal policy to a similarly unaccountable and independent FPC does not matter for stabilizing ex post deviations of actual inflation from target, in an analogous way to the ex ante formation of inflation expectations.

Corollary 2.2 All considered mechanisms for policymaking without accountability modeled as an override clause (Regimes A) also dominate the corresponding institutional contracts with accountability (Regimes B) in terms of resulting in lower deviation of actual inflation from target.

\section{Proof of Proposition 2 and the related corollaries 2.1 and 2.2}

A. Without Accountability Our extremes are, again, completely independent and unaccountable expert committees (Regime A2) versus a Government that optimizes alone (Regime A1). In Regime A2 (and A3), the deviation in question, $\pi-\pi^{e}$, is:

$$
\left(\pi-\pi^{e}\right)_{A 2, A 3}=\frac{\left(c \gamma_{y}^{M}\right)}{\gamma_{\pi}^{M}+c\left(c \gamma_{y}^{M}\right)} \varepsilon, \text { so that } 0<\text { Coeff. of } \varepsilon_{A 2, A 3}<1 \text {, }
$$

and the effect of the materialized aggregate supply disturbance, $\varepsilon$, on actual inflation and on the forecast error is thus dampened, the more so the higher is the MPC's preference weight on inflation, $\gamma_{\pi}^{M}$, and the more sensitive is aggregate supply to surprise inflation, i.e., the larger $c$.

At the other extreme, Regime A1 (and A4), the deviation $\pi-\pi^{e}$ is instead:

$$
\left(\pi-\pi^{e}\right)_{A 1, A 4}=\frac{\left(c \gamma_{y}^{G}\right)}{\gamma_{\pi}^{G}+c\left(c \gamma_{y}^{G}\right)} \varepsilon, \text { so that, again, } 0<\text { Coeff. of } \varepsilon_{A 1, A 4}<1,
$$


and the impact of the cost-push shock on actual inflation and on its deviation from expectations is dampened. However, insofar $\gamma_{\pi}^{G}<\gamma_{\pi}^{M}$ and $\gamma_{y}^{G}>\gamma_{y}^{M}$, the dampening effect is stronger on both counts in Regime A2 relative to Regime A1. Note that, again, Regime A2 is equivalent to Regime A3, and Regime A1 to A4 if the criterion for ranking is, like in the present subsection, the deviation of actual from expected inflation.

B. With Accountability Now the ranking is less evident, but we can show the following relations. We first compare Regimes $\mathrm{B} 2^{G}$ and $\mathrm{B} 2^{\text {com }}$. We form the difference $\pi_{B 2}^{G}-\pi_{B 2}^{c o m}=\left(\pi_{B 2}^{G}-\pi_{B 2}^{e}\right)-\left(\pi_{B 2}^{c o m}-\pi_{B 2}^{e}\right)$. There are three pairs of terms in the respective expressions for $\pi_{B 2}^{G}$ and $\pi_{B 2}^{c o m}$ that are different:

$$
\frac{c \gamma_{y}^{G}}{\kappa} \text { in } \pi_{B 2}^{G}<\frac{c \Omega}{\Pi+c^{2} \Omega} \text { in } \pi_{B 2}^{c o m}
$$

$(1-\alpha) c^{2} \gamma_{y}^{G}$ in the 2 nd term of $\pi_{B 2}^{G}<\kappa-\alpha c^{2} \gamma_{y}^{G}$ in the 2 nd term of $\pi_{B 2}^{c o m}$;

$\Pi+c^{2} \theta^{M} \gamma_{y}^{G}$ in the 4 th term of $\pi_{B 2}^{G}>\theta^{M} \kappa$ in the 4 th term of $\pi_{B 2}^{c o m}$.

The first pair of terms multiply the supply shock, $\varepsilon$; the second pair multiply the inflation target gap, $\pi^{*}-\pi^{*, G}<0$; and the third pair of terms multiply the output gap, $y^{*, G}-y^{N}>$ 0: on both counts, a smaller multiple to a negative term and a greater multiple to a positive term in the respective $(G$ versus com) actual inflation expressions for any realization of $\varepsilon$ (with the remaining terms in them being the same: compare Regime B2 with override versus committee decision in Appendix A):

$$
\pi_{B 2}^{G}>\pi_{B 2}^{c o m} \Leftrightarrow\left(\pi_{B 2}^{G}-\pi^{e}\right)>\left(\pi_{B 2}^{c o m}-\pi^{e}\right)
$$

i.e., $\mathrm{B} 2^{\text {com }}$ results in smaller deviations of actual inflation from target relative to $\mathrm{B} 2^{G}$.

We next argue that A2, in turn, results in even smaller deviations of actual inflation from target relative to B2 $2^{c o m}$, because: (i) $\pi_{B 2}^{c o m}$ is some weighted average of $\pi^{*}$ and $\pi^{*, G}$; (2) the supply shock multiplier in $\pi_{B 2}^{c o m}$ is bigger than that in $\pi_{A 2}$; and (iii) there are, furthermore, two positive terms added in $\pi_{B 2}^{c o m}$ which are absent in $\pi_{A 2}$.

So, $\mathrm{A} 2<\mathrm{B} 2^{\text {com }}<\mathrm{B} 2^{G}$ or $\mathrm{A} 2<\mathrm{B} 2$, i.e., Regime A2 (without accountability) leads to a smaller deviation of actual inflation from target relative to the corresponding Regime B2 (with accountability).

Similarly to the logic we exposed above, one can then also show that the remaining Regimes B, with accountability, are dominated by the respective Regimes A, without accountability, along the dimension of producing the lowest deviation of actual inflation from target. Hence, the best regime in terms of containing inflation following a cost-push shock is to design the MPC fully independent and unaccountable. This completes our proof of Proposition 2 and corollaries 2.1 and 2.2

The ranking according to our second criterion, in fact, a parallel image of the ranking along the criterion of anchoring inflation expectations, is summarized in the final column of Table 2. On account of both these criteria, therefore, (i) anchoring inflation expecta- 
tions (ex ante) and (ii) containing the effects of cost-push shocks on actual inflation (ex post), we have reached an unambiguous conclusion in terms of (a) the best regime as well as (b) the ordering of the alternative policy frameworks we considered here. ${ }^{15}$

[ Table 2 about here ]

\subsection{Ranking of Regimes by Actual Output Outcomes}

Besides inflation and inflation expectations, the output level is another key macroeconomic variable in our model: it is not an instrument itself, but is the only magnitude that plays an important role in all of the three objective functions.

A. Without Accountability The output levels that arise in the different policy regimes without accountability are all based on the normal output level and show different deviations from this benchmark. The deviations arise in regimes without accountability solely because of the supply shock. The impact of the demand shock is completely compensated by the policymakers. The influence of the supply shock on output depends on the preferences of the policymakers. In case of a positive (negative) supply shock, output is higher (lower) than normal. The size of the influence can be ordered as follows:

Proposition 3 Without accountability, the output level in Regime A1 is equal to the level in Regime A4 and the output level in Regime A2 is equal to the level in Regime A3. With $\gamma_{\pi}^{M} / \gamma_{y}^{M}>1>\gamma_{\pi}^{G} / \gamma_{y}^{G}$ and $\gamma_{\pi}^{M}>\gamma_{\pi}^{G}$, which is the assumed realistic situation in the model, the output level A1 and A4 is closer to normal output than the output level A2 and A3. In the general case $A$, the output level is intermediate between the polar regimes.

Proof of Proposition 3 To establish this result, we concentrate on the coefficient of the supply shock term in the output equations because the shock is the only source that drives output away from normal in all regimes:

$$
\begin{aligned}
& \text { Coeff. of } \varepsilon_{A 2, A 3}>\text { Coeff. of } \varepsilon_{A}>\text { Coeff. of } \varepsilon_{A 1, A 4}, \\
& \frac{\gamma_{\pi}^{M}}{\gamma_{\pi}^{M}+c^{2} \gamma_{y}^{M}}>\frac{\Pi}{\Pi+c^{2} \Omega}>\frac{\gamma_{\pi}^{G}}{\gamma_{\pi}^{G}+c^{2} \gamma_{y}^{G}} .
\end{aligned}
$$

The result is opposite to the one for expected inflation. For output, the deviation from normal level is highest if monetary policy is independent. If the Government dominates policymaking, output stabilization is according to its preferences. Because the MPC gives a higher priority to bringing inflation back to target rather than output compared

\footnotetext{
${ }^{15}$ The unambiguous ranking of actual inflation outcomes across regimes arises because deviations from expected inflation are considered that results only due to the supply shock. If absolute levels of inflation rates are compared instead, a similar ambiguity as in the case of output levels arises and target differences play a role in addition to the supply shock as discussed next. A comparison of the inflation rate determined by the Government with the one determined by the committees in Regime B with accountability shows that there is a realization of the supply shock where the inflation rates are equal. The shock is of the same size as the one that equates the output levels, $y^{G}$ and $y^{\text {com }}$ in Regime B (see equation (10)).
} 
to the Government, it is not surprising that a supply shock has a larger impact on the output level if the MPC is independent and can stabilize according to its own preferences only. In the general case of Regime A, shock stabilization is a "weighted average" of the preferences of the Government and the MPC, where the weight is according to the degree of independence of the MPC. In this case, an intermediate level of shock stabilization arises. This completes our proof of Proposition 3

B. With Accountability When the MPC and the FPC can be made accountable in the sense implied by our model, and, in case of large supply shocks, are overridden by the Government, in each regime two different output levels can arise. The Government determines both the interest rate and the deficit, and this results in a particular output level, with probability $\alpha$. With probability $1-\alpha$, the MPC and the FPC each determine their instrument and "tie" the output level down. As soon as the MPC is not completely independent, the output level is not only influenced by normal output and the supply shock but also by the difference between the Government's inflation target and the MPC's target as well as by the gap between the output target of the Government and normal output being the target of the MPC and the FPC. This result comes from the uncertainty of the private sector which institution would be the policymaker in charge when forming inflation expectations.

Unlike in the formation of inflation expectations, the probability of overriding does not play a role in shock stabilization since this task is done after the authority in charge of economic policy is determined ex post. When the private sector forms expectations, shock stabilization does not matter because of an expected shock value of zero; therefore, which authority stabilizes the shock does not matter either.

Moreover, only the degree of dependence of the MPC matters for the output level: the case of a completely independent MPC leads to the same output level regardless whether the FPC is completely independent or completely dependent (Regimes B2 and B3). Again, normal output is the starting point for actual output. However, there is an additional influence of the normal output level on actual output that increases its impact above unity. The size of the effect depends on the degree of independence of the MPC, the probability of overriding, and the preferences of the Government and the MPC with regard to inflation and the output gap.

Proposition 4 If the Government ultimately determines the instruments in the regimes with accountability, the output level in Regime B1 equals that of Regime B4 and the output level in Regime B2 equals that of B3. The output level in B1 and B4 is lower and closer to the normal level compared to the output levels in all other regimes. The output level in $B 2$ is higher than in B. If the committees are left to decide instead, the net effect is ambiguous and ranking is not possible.

Proof of Proposition 4 If the MPC is completely dependent, shock stabilization is determined by the Government only and, therefore, only Government preferences deter- 
mine the output level (Regimes B1 and B4). Output only deviates from normal level because of the supply shock. However, if monetary policy is not completely dependent on Government preferences, the Government takes into account the MPC preferences via inflation expectations. In this case, output increases because of the overambitious target levels of the Government, $y^{*, G}>y^{N}$ and $\pi^{*, G}>\pi^{*}$. The impact of the normal output level on output besides the difference to the Government target is positive regardless of the regime with accountability. The highest output level is reached if the Government overrides the completely independent MPC (Regimes B2 and B3). Here, agents expect especially low inflation and, therefore, the Government can raise output exceptionally high with lower reaction of the inflation rate than with only partial independence.

If the committees are left to determine the instrument level under accountability, the results have the same structure as in the regimes where the Government steps in. However, the effects of the gap between the inflation targets of the Government and the committees and the gap between the output target of the Government and normal output have the opposite sign. The committees determine the instrument level in a way that these gaps now have a negative influence on the output level. The respective influences are of the same magnitude as when the Government overrides the committees but weighted with the probability that the Government does not step in, $1-\alpha$, instead of $\alpha$. The influence of the normal output level besides that of the difference to the Government target is of the same size and magnitude as in the case where the Government finally decides. Moreover, the influence of the supply shock is higher if the committees are not overridden because they have a lower preference for output stabilization. If the committees decide, output would be lower as a rule compared to Government decisions. However, there is a range for positive supply shocks where $y^{\text {com }}>y^{G}$ and for

$$
\varepsilon=\frac{\gamma_{\pi}^{M} \kappa\left(\Pi+c^{2} \Omega\right)}{\Lambda c \omega}\left[\gamma_{\pi}^{G}\left(\pi^{*, G}-\pi^{*}\right)+c \gamma_{y}^{G}\left(y^{*, G}-y^{N}\right)\right]
$$

in the general case. Figure 1 shows the basic mechanism that leads to this result and that also applies to all other comparisons of output outcomes when the committees are involved.

The starting point is the normal output level multiplied with a term that is higher than one. Because the weighting of normal output is the same regardless whether the Government or the committees decide, we observe deviation from that level. First, a deviation occurs because of the impact of the supply shock that is partly accommodated by the policymaker in charge. Because the Government has higher preferences for output on target, the deviation from normal output is lower for the Government policies. This leads to a higher Government output level in case of a negative and a lower level in case of a positive supply shock compared to the respective committee levels. Second, the target differences also lead to a deviation from normal output but in an unambiguous way; output with the Government in charge is always higher. However, there is a range 


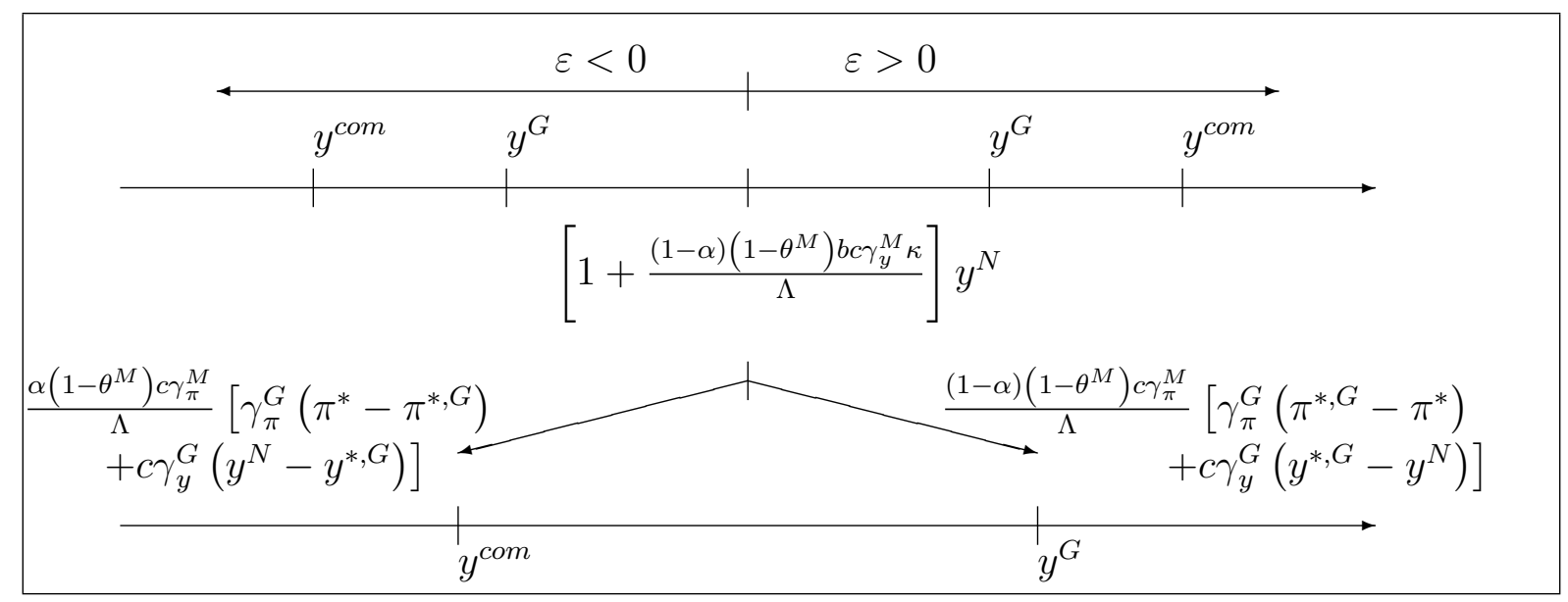

Figure 1: The influences on the output level when the Government decides and when the committees decide in the general case with accountability.

where the Government level of output is lower than the committee level because of the stronger stabilization. This completes our proof of Proposition 4

Corollary 4.1 Comparing the policy regimes with and without accountability, Regime A1 and A4 produce the same output level as Regime B1 and B4. For all other regimes, the relationship between the output levels is ambiguous.

Proof of Corollary 4.1 If monetary policy is completely dependent, only Government preferences determine output stabilization and output deviates from the normal level only because of supply shocks. In addition, no target deviations occur, so that without shocks output always equals its normal level. In this case, there is no difference between the regimes with and without accountability (Regimes 1 and 4). This also confirms the presumption that it is not reasonable to hold a completely dependent authority accountable. Because of the above-established equality between Regimes A1, B1, A4 and $\mathrm{B} 4$, the results from the previous proposition directly carry over to the comparison between the output outcome of the regimes with and without accountability.

For output stabilization across responsibilities and accountability regimes, the following results can be established:

Coeff. of $\varepsilon_{A 1, A 4, B 1, B 4}=$ Coeff. of $\varepsilon_{B 2, B 3}^{G}<$ Coeff. of $\varepsilon_{A 2, A 3}=$ Coeff. of $\varepsilon_{B 2, B 3}^{c o m}$,

$$
\frac{\gamma_{\pi}^{G}}{\gamma_{\pi}^{G}+c^{2} \gamma_{y}^{G}}<\frac{\gamma_{\pi}^{M}}{\gamma_{\pi}^{M}+c^{2} \gamma_{y}^{M}}
$$

The highest degree of output stabilization is achieved if the Government is in charge of monetary policy. This can be the case without accountability when the committees are completely dependent (Regimes $\mathrm{A} 1(=\mathrm{B} 1)=\mathrm{A} 4(=\mathrm{B} 4))$, and with accountability when the Government overrides (Regimes B2, B3). In each case, shock stabilization occurs with regard to Government preferences only. For shock stabilization, accountability does not matter because the policymakers decide about stabilization if they have the power to do 
so and private agents do not expect shocks on average. Therefore, only own preferences play any role.

Because target differences only occur in regimes with accountability, output is higher (lower) compared to regimes without accountability if the Government (the committees) is (are) in charge and if monetary policy is not completely dependent. Because target differences between the Government and the committees are negative in cases where the committees decide, the net effect is not clear since such differences point in the opposite direction compared to the positive effect of the normal output level. If the Government is in charge, the net effect is unambiguously positive, when putting aside the supply shock. This completes our proof of Corollary 4.1

A summary of our results on the ranking of the considered policy regimes according to actual output is provided in Table 3 .

[ Table 3 about here ]

\subsection{Ranking of Regimes by Actual Deficit Outcomes}

In opposition to the interest rate, the budget deficit has a twofold role to play in our model. First, it is an instrument to stimulate demand. Second, it is a target in the loss functions of the Government and the FPC.

Proposition 5 In all regimes where the Government can decide on monetary and fiscal policy jointly, the budget deficit will equal the Government target.

Proof of Proposition 5 The Government will establish the deficit on target if the monetary and fiscal authorities are completely dependent and implement policy according to the preferences of the Government as well as if it overrides committee decisions in the regimes with accountability. If both instruments are optimized jointly, then the deficit is not needed to influence inflation and output: the interest rate is sufficient as policy instrument. To get this result, a dependent fiscal policy is not enough; monetary policy has to be dependent too.

The starting point in analyzing the deficit is a deficit target value independent of whether accountability is intended or not. In cases where fiscal policy is dependent, the target equals that of the Government. With independent fiscal policy, the target of the FPC prevails. With intermediate values of FPC independence, a weighted average of the targets can be observed depending on the degree of fiscal policy autonomy.

A. Without Accountability If no accountability of the committees is intended, the deficit reacts not only to the target level but decreases (increases) with positive (negative) supply shocks. Ranking the regimes without accountability according to the reaction to supply shocks, Regime A1 does not show any influence of supply shocks. In Regime A2, the influence of the supply shock is larger than in Regime A4. A ranking of the other regimes according to the shock is not possible. The reaction of the deficit to supply 
shocks in regimes with accountability is the same as in the respective A regimes if the committees are left to decide. If the Government overrides, there is no influence of the shock. The relation between the influence of the supply shock on the deficit level in Regimes A2 and A3 looks as follows:

$$
\frac{\gamma_{\pi}^{M}}{\gamma_{y}^{M}}\left(\frac{\gamma_{d}^{F}}{\gamma_{y}^{F}}-\frac{\gamma_{d}^{G}}{\gamma_{y}^{G}}\right) \gtreqless \frac{\gamma_{\pi}^{G} \gamma_{d}^{F}}{\gamma_{y}^{G} \gamma_{y}^{F}}
$$

and the corresponding relation in Regimes A3 and A4 is given by:

$$
\frac{\frac{\gamma_{\pi}^{G}}{\gamma_{d}^{G}}}{\frac{\gamma_{\pi}^{M}}{\gamma_{y}^{M}}} \frac{\gamma_{\pi}^{M}}{\gamma_{\pi}^{M}+c^{2} \gamma_{y}^{M}} \gtreqless \frac{\gamma_{y}^{G}}{\gamma_{d}^{G}} \frac{\gamma_{\pi}^{M}}{\gamma_{\pi}^{M}+c^{2} \gamma_{y}^{M}}-\frac{\gamma_{y}^{F}}{\gamma_{d}^{F}} \frac{\gamma_{\pi}^{G}}{\gamma_{\pi}^{G}+c^{2} \gamma_{y}^{G}}
$$

In addition to supply shocks, the deficit reacts to the difference between the inflation and output targets of the committees and the Government if monetary policy is completely independent but fiscal policy is not (Regime A3) and if both committees are partially independent (Regimes A). In these cases, the Government tries to offset some influence of the independent determination of the interest rate. If monetary policy is completely dependent but fiscal policy independent, such effects do not occur.

B. With Accountability In regimes with accountability, target differences play a role if the committees are not overridden and are partially independent (Regimes B) or where monetary policy is completely independent (Regimes B2 and B3). With independent monetary policy, the deficit reacts in a stronger way to the target differences if fiscal policy is dependent on Government preferences. The deficit is then used as an instrument to achieve the overambitious output target of the Government.

If the Government decides alone, the deficit is always on target and not needed for stabilization purposes or aiming at target levels for inflation and output. A ranking of the deficit when the committees are not overridden by the Government looks as follows. In Regime B1 with completely dependent committees, the deficit is on target. If the FPC is made independent, it also reacts to shocks but introduces a lower target level. If the MPC is made completely independent, there is also a reaction to the target differences that is more aggressive (stronger) with a dependent FPC. But the reaction to shocks cannot be compared between the two regimes with completely independent MPC. This completes our proof of Proposition 5

We summarize our findings on the comparison of regimes along the dimension of the public deficit in Table 4.

[ Table 4 about here ] 


\section{Concluding Remarks}

This paper set as its objective to address the important issue of independence and accountability of delegated monetary and fiscal policy. In a theoretical model allowing for different degrees of autonomy of expert committees to which the government may opt to delegate both monetary and fiscal policy as well as for subsequent interactions, we analyze the effects of democratic accountability in the form of possible overriding of committee decisions. As the literature on monetary policy has usually established, we also find that delegation of decision-making to autonomous institutions of appointed experts improves the outcomes in terms of average inflation performance over policies conducted by elected and self-interested governments. In other words, independent monetary and fiscal authorities operating within clear mandates solve the problem of inflationary bias by anchoring inflation expectations on target. However, our work clearly points out that there is more to that aspect in evaluating the independence of policymakers once accountability is also explicitly considered.

A fully independent non-elected MPC whose decisions are explicitly guaranteed not to be overridden by, and in the latter context unaccountable to, elected politicians is the institution-design regime we found to implement the lowest anchoring of inflation expectations. Once monetary policy is delegated to such an expert committee, delegation or not of fiscal policy as well to a parallel independent FPC does not matter for inflation expectations in our set-up. Along this same dimension, all considered mechanisms for policymaking without the possibility of overriding dominate the corresponding mechanisms with accountability.

However, we derived an opposite result in terms of regime ordering when ex post output stabilization was chosen instead as the unique criterion for selecting the socially optimal policy. Because the government, aiming at re-election, is more concerned about meeting the output target, the highest output stabilization arises if its preferences alone determine stabilization: either in the case where monetary policy is completely dependent, or when the government overrides MPC's decisions. The impact of lower output stabilization by the committees will be bounded because the government steps in if large supply shocks occur and dampens the effects according to its higher stabilization preferences.

Overall, applying any combination of the above considerations as a multiple criterion to rank the examined institution-design mechanisms may give priority to either anchoring inflation expectations ex ante, and hence also stabilizing ex post inflation, or to output stabilization, possibly constrained by attaining the target for the public-sector deficit too. This is, certainly, a political trade-off, and any solution to it would be chosen in each relevant real-world context with view to the preferences of society and its democratic representatives, as well as the economic environment and the institutional framework for policymaking. What we can conclude from our theoretical exercise is that if the priority is to manage inflation and inflation expectations, a society should opt for independent monetary policy which is free from the threat of its decisions being overridden. If, on 
the other hand, a society would prefer to mitigate the fluctuations of output and employment, policymaking by expert committees should be additionally constrained either by limits to independence, e.g., permitting instrument- but not goal-independence, as in popular inflation targeting regimes of monetary policy, or by accountability mechanisms such as override clauses or more sophisticated contractual arrangements with broadly similar effects. A combination of both these restrictive institutional devices, one acting upon the degree of independence and the other upon the degree of accountability, is also envisageable - as well as any intermediate policy regimes between the polar cases - depending on the priorities and corresponding trade-offs a democratic society is prepared to accept and implement. 


\section{A Model Solution}

Throughout, we will use the following abbreviations:

$$
\begin{gathered}
\Delta:=\theta^{F} \gamma_{d}^{G}+\left(1-\theta^{F}\right) \gamma_{d}^{F}, \quad \Upsilon:=\theta^{F} \gamma_{y}^{G}+\left(1-\theta^{F}\right) \gamma_{y}^{F}, \\
\Pi:=\theta^{M} \gamma_{\pi}^{G}+\left(1-\theta^{M}\right) \gamma_{\pi}^{M}, \quad \Omega:=\theta^{M} \gamma_{y}^{G}+\left(1-\theta^{M}\right) \gamma_{y}^{M}, \\
\kappa:=\gamma_{\pi}^{G}+c^{2} \gamma_{y}^{G}, \quad \varphi:=\gamma_{\pi}^{M}+c^{2} \gamma_{y}^{M}, \quad \omega:=\gamma_{y}^{G} \gamma_{\pi}^{M}-\gamma_{\pi}^{G} \gamma_{y}^{M}, \quad \Lambda:=\kappa \Pi-\alpha\left(1-\theta^{M}\right) c^{2} \omega .
\end{gathered}
$$

\section{Delegation of Economic Policy without Accountability}

Regime A: General-Case Solution: Partial Independence without Accountability

We derive the following equilibrium outcomes for the deficit, the inflation rate, inflation expectations and output:

$$
\begin{aligned}
d= & \frac{\theta^{F} \gamma_{d}^{G} d^{*, G}+\left(1-\theta^{F}\right) \gamma_{d}^{F} d^{*}}{\Delta}+\frac{a\left(1-\theta^{M}\right) \theta^{F}}{\Delta \Pi}\left[\frac{\gamma_{\pi}^{G} \gamma_{\pi}^{M}}{c}\left(\pi^{*, G}-\pi^{*}\right)+\left(\gamma_{\pi}^{M} \gamma_{y}^{G} y^{*, G}-\gamma_{\pi}^{G} \gamma_{y}^{M} y^{N}\right)\right] \\
& -\frac{a\left[\left(1-\theta^{M}\right) \theta^{F} \omega+\left(1-\theta^{F}\right) \gamma_{y}^{F} \Pi\right]}{\left(\Pi+c^{2} \Omega\right) \Delta} \varepsilon, \\
\pi= & \frac{\theta^{M} \gamma_{\pi}^{G}}{\Pi} \pi^{*, G}+\frac{\left(1-\theta^{M}\right) \gamma_{\pi}^{M}}{\Pi} \pi^{*}+\frac{c \theta^{M} \gamma_{y}^{G}}{\Pi}\left(y^{*, G}-y^{N}\right)-\frac{c \Omega}{\Pi+c^{2} \Omega} \varepsilon \\
\pi^{e}= & \frac{\theta^{M} \gamma_{\pi}^{G}}{\Pi} \pi^{*}+\frac{\left(1-\theta^{M}\right) \gamma_{\pi}^{M}}{\Pi} \pi^{*}+\frac{c \theta^{M} \gamma_{y}^{G}}{\Pi}\left(y^{*, G}-y^{N}\right), \\
y= & y^{N}+\frac{\Pi}{\Pi+c^{2} \Omega} \varepsilon .
\end{aligned}
$$

Special-Case Solutions without Accountability

Regime A1: Government Optimization without Accountability This regime results in the following equilibrium equations for the deficit, inflation, inflation expectations and output:

$$
\begin{aligned}
d & =d^{*, G} \\
\pi & =\pi^{*, G}+\frac{c \gamma_{y}^{G}}{\gamma_{\pi}^{G}}\left(y^{*, G}-y^{N}\right)-\frac{c \gamma_{y}^{G}}{\kappa} \varepsilon, \\
\pi^{e} & =\pi^{*, G}+\frac{c \gamma_{y}^{G}}{\gamma_{\pi}^{G}}\left(y^{*, G}-y^{N}\right), \\
y & =y^{N}+\frac{\gamma_{\pi}^{G}}{\kappa} \varepsilon .
\end{aligned}
$$


Regime A2: Independent and Unaccountable Committees The deficit, actual inflation, inflation expectations and the output level are given by

$$
\begin{aligned}
d & =d^{*}-\frac{\gamma_{\pi}^{M} \gamma_{y}^{F} a}{\varphi \gamma_{d}^{F}} \varepsilon, \\
\pi & =\pi^{*}-\frac{c \gamma_{y}^{M}}{\varphi} \varepsilon, \\
\pi^{e} & =\pi^{*} \\
y & =y^{N}+\frac{\gamma_{\pi}^{M}}{\varphi} \varepsilon .
\end{aligned}
$$

Regime A3: Independent and Unaccountable MPC with Completely Dependent FPC The resulting equation for the deficit is

$$
d=d^{*, G}+\frac{a}{\gamma_{d}^{G}}\left[\frac{\gamma_{\pi}^{G}}{c}\left(\pi^{*, G}-\pi^{*}\right)+\gamma_{y}^{G}\left(y^{*, G}-y^{N}\right)\right]-\frac{a \omega}{\varphi \gamma_{d}^{G}} \varepsilon .
$$

The inflation rate, inflation expectations and output are the same as in Regime A2.

Regime A4: Independent and Unaccountable FPC with Completely Dependent MPC In this case, the deficit is given by

$$
d=d^{*}-\frac{\gamma_{\pi}^{G} \gamma_{y}^{F} a}{\kappa \gamma_{d}^{F}} \varepsilon
$$

Actual inflation, inflation expectations and output are the same as in Regime A1. 


\section{Delegation of Economic Policy with Accountability}

\section{Regime B: General-Case Solution: Partial Independence with Accountability}

If a large supply shock occurs and the Government overrides the decisions of the FPC and the $M P C$

$$
\begin{aligned}
d^{G}= & d^{*, G}, \\
\pi^{e}= & \pi^{*, G}+\frac{(1-\alpha)\left(1-\theta^{M}\right) \gamma_{\pi}^{M} \kappa}{\Lambda}\left(\pi^{*}-\pi^{*, G}\right)+\frac{c \gamma_{y}^{G}\left[\theta^{M} \kappa+\alpha\left(1-\theta^{M}\right) \varphi\right]}{\Lambda}\left(y^{*, G}-y^{N}\right) \\
& +\frac{(1-\alpha)\left(1-\theta^{M}\right) c \gamma_{y}^{M} \kappa}{\Lambda} y^{N}, \\
\pi^{G}= & \pi^{*, G}+\frac{(1-\alpha)\left(1-\theta^{M}\right) c^{2} \gamma_{y}^{G} \gamma_{\pi}^{M}}{\Lambda}\left(\pi^{*}-\pi^{*, G}\right)-\frac{c \gamma_{y}^{G}}{\kappa} \varepsilon \\
& +\frac{c \gamma_{y}^{G}\left[\Pi+c^{2} \theta^{M} \gamma_{y}^{G}+\alpha c^{2}\left(1-\theta^{M}\right) \gamma_{y}^{M}\right]}{\Lambda}\left(y^{*, G}-y^{N}\right)+\frac{(1-\alpha)\left(1-\theta^{M}\right)(b+c) \gamma_{y}^{M} \kappa}{\Lambda} y^{N}, \\
y^{G}= & y^{N}+\frac{(1-\alpha)\left(1-\theta^{M}\right) c \gamma_{\pi}^{M}}{\Lambda}\left[\gamma_{\pi}^{G}\left(\pi^{*, G}-\pi^{*}\right)+c \gamma_{y}^{G}\left(y^{*, G}-y^{N}\right)\right] \\
& +\frac{(1-\alpha)\left(1-\theta^{M}\right) b c \gamma_{y}^{M} \kappa}{\Lambda} y^{N}+\frac{\gamma_{\pi}^{G}}{\kappa} \varepsilon .
\end{aligned}
$$

If a small supply shock occurs and the FPC and the MPC are left to decide

$$
\begin{aligned}
d^{\text {com }}= & \frac{\theta^{F} \gamma_{d}^{G} d^{*, G}+\left(1-\theta^{F}\right) \gamma_{d}^{F} d^{*}}{\Delta}-\frac{a\left[\left(1-\theta^{M}\right) \theta^{F} \omega+\left(1-\theta^{F}\right) \gamma_{y}^{F} \Pi\right]}{\Delta\left[\Pi+c^{2} \Omega\right]} \varepsilon \\
& +\frac{a\left(1-\theta^{M}\right) \gamma_{\pi}^{M}\left[\theta^{F} \kappa+\alpha\left(1-\theta^{F}\right) c^{2} \gamma_{y}^{F}\right]}{\Delta \Lambda}\left[\frac{\gamma_{\pi}^{G}}{c}\left(\pi^{*, G}-\pi^{*}\right)+\gamma_{y}^{G}\left(y^{*, G}-y^{N}\right)\right],
\end{aligned}
$$

$\pi^{e} \quad$ the same as if the Government overrides,

$$
\begin{aligned}
\pi^{c o m}= & \pi^{*, G}+\frac{\left(1-\theta^{M}\right) \gamma_{\pi}^{M}\left(\kappa-\alpha c^{2} \gamma_{y}^{G}\right)}{\Lambda}\left(\pi^{*}-\pi^{*, G}\right)-\frac{c \Omega}{\Pi+c^{2} \Omega} \varepsilon \\
& +\frac{c \gamma_{y}^{G}\left[\theta^{M} \kappa+\alpha\left(1-\theta^{M}\right) c^{2} \gamma_{y}^{M}\right]}{\Lambda}\left(y^{*, G}-y^{N}\right)+\frac{(1-\alpha)\left(1-\theta^{M}\right)(b+c) \gamma_{y}^{M} \kappa}{\Lambda} y^{N}, \quad \text { (A-20) } \\
y^{c o m}= & y^{N}+\frac{\alpha\left(1-\theta^{M}\right) c \gamma_{\pi}^{M}}{\Lambda}\left[\gamma_{\pi}^{G}\left(\pi^{*}-\pi^{*, G}\right)+c \gamma_{y}^{G}\left(y^{N}-y^{*, G}\right)\right]+\frac{(1-\alpha)\left(1-\theta^{M}\right) b c \gamma_{y}^{M} \kappa}{\Lambda} y^{N} \\
& +\frac{\Pi}{\Pi+c^{2} \Omega} \varepsilon .
\end{aligned}
$$

\section{Special-Case Solutions with Accountability}

Regime B1: Government Optimization with Accountability The results are the same as if the Government would minimize the loss from start. In this case, the results are the same as in Regime A1, regardless whether the committees or the Government decide. 
With complete dependence, the committees only would implement the instruments that are determined according to Government preferences and targets.

Regime B2: Independent but Accountable Committees If a large supply shock occurs and the Government overrides the decisions of the FPC and the MPC

$$
\begin{aligned}
d^{G}= & d^{*, G} \\
\pi^{e}= & \frac{(1-\alpha) \kappa \gamma_{\pi}^{M} \pi^{*}+\alpha \varphi \gamma_{\pi}^{G} \pi^{*, G}}{\gamma_{\pi}^{M} \kappa-\alpha c^{2} \omega}+\frac{c\left[(1-\alpha) \kappa \gamma_{y}^{M} y^{N}+\alpha \varphi \gamma_{y}^{G}\left(y^{*, G}-y^{N}\right)\right]}{\gamma_{\pi}^{M} \kappa-\alpha c^{2} \omega} \\
\pi^{G}= & \pi^{*, G}+\frac{(1-\alpha) c^{2} \gamma_{y}^{G} \gamma_{\pi}^{M}}{\gamma_{\pi}^{M} \kappa-\alpha c^{2} \omega}\left(\pi^{*}-\pi^{*, G}\right)-\frac{c \gamma_{y}^{G}}{\kappa} \varepsilon \\
& +\frac{c \gamma_{y}^{G}\left(\gamma_{\pi}^{M}+\alpha c^{2} \gamma_{y}^{M}\right)}{\gamma_{\pi}^{M} \kappa-\alpha c^{2} \omega}\left(y^{*, G}-y^{N}\right)+\frac{(1-\alpha)(b+c) \gamma_{y}^{M} \kappa}{\gamma_{\pi}^{M} \kappa-\alpha c^{2} \omega} y^{N} \\
y^{G}= & y^{N}+\frac{(1-\alpha) c \gamma_{\pi}^{M}}{\gamma_{\pi}^{M} \kappa-\alpha c^{2} \omega}\left[\gamma_{\pi}^{G}\left(\pi^{*, G}-\pi^{*}\right)+c \gamma_{y}^{G}\left(y^{*, G}-y^{N}\right)\right]+\frac{(1-\alpha) b c \gamma_{y}^{M} \kappa}{\gamma_{\pi}^{M} \kappa-\alpha c^{2} \omega} y^{N}+\frac{\gamma_{\pi}^{G}}{\kappa} \varepsilon
\end{aligned}
$$

If a small supply shock occurs and the FPC and the MPC are left to decide

$$
\begin{aligned}
d^{c o m}= & d^{*}-\frac{\gamma_{\pi}^{M} \gamma_{y}^{F} a}{\varphi \gamma_{d}^{F}} \varepsilon+\frac{\alpha a c \gamma_{\pi}^{M} \gamma_{y}^{F}}{\gamma_{d}^{F}\left(\gamma_{\pi}^{M} \kappa-\alpha c^{2} \omega\right)}\left[\gamma_{\pi}^{G}\left(\pi^{*, G}-\pi^{*}\right)+\gamma_{y}^{G} c\left(y^{*, G}-y^{N}\right)\right] \\
\pi^{e} \quad & \text { the same as if the Government overrides } \\
\pi^{c o m}= & \pi^{*, G}+\frac{\gamma_{\pi}^{M}\left(\kappa-\alpha c^{2} \gamma_{y}^{G}\right)}{\gamma_{\pi}^{M} \kappa-\alpha c^{2} \omega}\left(\pi^{*}-\pi^{*, G}\right)-\frac{c \gamma_{y}^{M}}{\varphi} \varepsilon+\frac{\alpha c^{3} \gamma_{y}^{G} \gamma_{y}^{M}}{\gamma_{\pi}^{M} \kappa-\alpha c^{2} \omega}\left(y^{*, G}-y^{N}\right) \\
& +\frac{(1-\alpha)(b+c) \gamma_{y}^{M} \kappa}{\gamma_{\pi}^{M} \kappa-\alpha c^{2} \omega} y^{N}, \\
y^{c o m}= & y^{N}+\frac{(1-\alpha) b c \gamma_{y}^{M} \kappa}{\gamma_{\pi}^{M} \kappa-\alpha c^{2} \omega} y^{N}+\frac{\alpha c \gamma_{\pi}^{M}}{\gamma_{\pi}^{M} \kappa-\alpha c^{2} \omega}\left[\gamma_{\pi}^{G}\left(\pi^{*}-\pi^{*, G}\right)+c \gamma_{y}^{G}\left(y^{N}-y^{*, G}\right)\right]+\frac{\gamma_{\pi}^{M}}{\varphi} \varepsilon
\end{aligned}
$$

Regime B3: Independent but Accountable MPC with Completely Dependent FPC If a large supply shock occurs and the Government overrides the decision of the $M P C$, the deficit, the inflation rate, inflation expectations and output are the same as in Regime B2. If a small supply shock occurs and the MPC is left to decide

$$
d^{c o m}=d^{*, G}-\frac{a \omega}{\varphi \gamma_{d}^{G}} \varepsilon+\frac{a \gamma_{\pi}^{M} \kappa}{\left(\gamma_{\pi}^{M} \kappa-\alpha c^{2} \omega\right) \gamma_{d}^{G}}\left[\frac{\gamma_{\pi}^{G}}{c}\left(\pi^{*, G}-\pi^{*}\right)+\gamma_{y}^{G}\left(y^{*, G}-y^{N}\right)\right] .
$$

The inflation rate, inflation expectations and output are the same as in Regime B2.

\section{Regime B4: Independent but Accountable FPC with Completely Dependent}

MPC If the Government overrides, it will implement $d^{G}=d^{*, G}$ but inflation, inflation expectations and output would be the same as if the FPC would determine its instrument level. 


\section{B Summary Tables}

\begin{tabular}{llll}
\hline Regime & Parameter setting & $\begin{array}{l}\text { Without } \\
\text { accountability, } \\
\alpha=0\end{array}$ & $\begin{array}{l}\text { With } \\
\text { accountability, } \\
0<\alpha \leq 1\end{array}$ \\
\hline \hline General Case: Partial Independence & $\begin{array}{l}0<\theta^{M}<1, \\
0<\theta^{F}<1\end{array}$ & Regime A & Regime B \\
Special Cases: & $\theta^{M}=1, \theta^{F}=1$ & Regime A1 & Regime B1 \\
Government Optimization & $\theta^{M}=0, \theta^{F}=0$ & Regime A2 & Regime B2 \\
Independent Committees & $\theta^{M}=0, \theta^{F}=1$ & Regime A3 & Regime B3 \\
Independent MPC, Dependent FPC & $\theta^{M}=1, \theta^{F}=0$ & Regime A4 & Regime B4 \\
\hline Independent FPC, Dependent MPC
\end{tabular}

Table 1: Overview of the different policy regimes depending on the degree of independence and accountability of the committees

\begin{tabular}{|c|c|c|}
\hline & $\pi^{e}$ & $\pi-\pi^{*}$ \\
\hline $\begin{array}{c}\text { A } \\
\text { A1 } \\
\text { A2 } \\
\text { A3 } \\
\text { A4 }\end{array}$ & $\begin{array}{c}2, \text { if } 0<\theta^{M}<\frac{1}{2} \\
\text { or } 3 \text { if } \frac{1}{2}<\theta^{M}<1 \\
4 \\
1 \\
1 \\
4\end{array}$ & $\begin{array}{c}2, \text { if } 0<\theta^{M}<\frac{1}{2} \\
\text { or } 3 \text { if } \frac{1}{2}<\theta^{M}<1 \\
4 \\
1 \\
1 \\
4\end{array}$ \\
\hline $\begin{array}{c}\mathrm{B} \\
\mathrm{B} 1 \\
\mathrm{~B} 2 \\
\mathrm{~B} 2^{G} \\
\mathrm{~B} 2^{\text {com }} \\
\mathrm{B} 3 \\
\mathrm{~B} 4\end{array}$ & $\begin{array}{c}\text { dominated by A } \\
4 \\
\text { dominated by A2 } \\
- \\
- \\
\text { dominated by A3 } \\
4\end{array}$ & $\begin{array}{c}\text { dominated by } \mathrm{B} 2=\mathrm{B} 3 \\
=\mathrm{B} 4=\mathrm{A} 4=\mathrm{A} 1, \text { dominated by } \mathrm{B} 2=\mathrm{B} 3 \\
\text { dominated by } \mathrm{A} 2=\mathrm{A} 3 \\
=\mathrm{B} 3^{G} \text { dominated by } \mathrm{B} 2^{\mathrm{com}}=\mathrm{B} 3^{\mathrm{com}} \\
=\mathrm{B} 3^{\text {com }} \text { dominated by } \mathrm{A} 2=\mathrm{A} 3 \\
=\mathrm{B} 2, \text { dominated by } \mathrm{A} 3=\mathrm{A} 2 \\
=\mathrm{B} 1, \text { dominated by } \mathrm{B} 2=\mathrm{B} 3\end{array}$ \\
\hline
\end{tabular}

Table 2: Ranking of expected and actual inflation outcomes across policy regimes (1 - closest to target value, 4 - largest deviation from target value) 


\begin{tabular}{|c|c|c|c|c|}
\hline Regime & shock stabilization & \multicolumn{2}{|c|}{$\begin{array}{c}\text { target differences } \\
\pi^{*, G}-\pi^{*}>0, y^{*, G}-y^{*}>0 \\
\text { sign } \quad \text { size (absolute value) }\end{array}$} & $\begin{array}{l}\text { normal output level } \\
\qquad y^{N}\end{array}$ \\
\hline $\mathrm{A}$ & $A 1<A<A 2$ & & - & $=1$ \\
\hline $\mathrm{A} 1$ & $A 1<A<A 2$ & & - & $=1$ \\
\hline $\mathrm{A} 2$ & $A 1<A<A 2$ & & - & $=1$ \\
\hline A3 & $=A 2$ & & - & $=1$ \\
\hline $\mathrm{A} 4$ & $=A 1$ & & - & $=1$ \\
\hline $\mathrm{B}^{G}$ & $=A 1$ & $>0$ & $B^{G}<B 2^{G}$ & $B 2^{G}>B^{G}>1$ \\
\hline $\mathrm{B}^{\mathrm{com}}$ & $=A$ & $<0$ & $B^{c o m}<B 2^{c o m}$ & $=B^{c o m}>1$ \\
\hline $\mathrm{B} 1^{G}$ & $=A 1$ & - & - & $=A 1=1$ \\
\hline $\mathrm{B} 1^{\mathrm{com}}$ & $=A 1$ & - & - & $=A 1=1$ \\
\hline $\mathrm{B} 2^{G}$ & $=A 1$ & $>0$ & & $B 2^{G}>1$ \\
\hline $\mathrm{B} 2^{\mathrm{com}}$ & $=A 2$ & $<0$ & & $=B 2^{c o m}>1$ \\
\hline & & & $\begin{array}{c}B 2^{G} \geq(\leq) B 2^{\text {com }} \\
\quad \text { if } \alpha \leq(\geq) \frac{1}{2}\end{array}$ & \\
\hline $\mathrm{B} 3^{G}$ & $=A 1$ & $>0$ & $=B 2^{G}$ & $=B 2^{G}$ \\
\hline $\mathrm{B} 3^{\mathrm{com}}$ & $=A 2$ & $<0$ & $=B 2^{c o m}$ & $=B 2^{\mathrm{com}}$ \\
\hline $\mathrm{B} 4^{G}$ & $=A 1$ & - & - & $=A 1=1$ \\
\hline $\mathrm{B} 4^{\mathrm{com}}$ & $=A 1$ & - & - & $=A 1=1$ \\
\hline
\end{tabular}

Table 3: Ranking of output outcomes across policy regimes

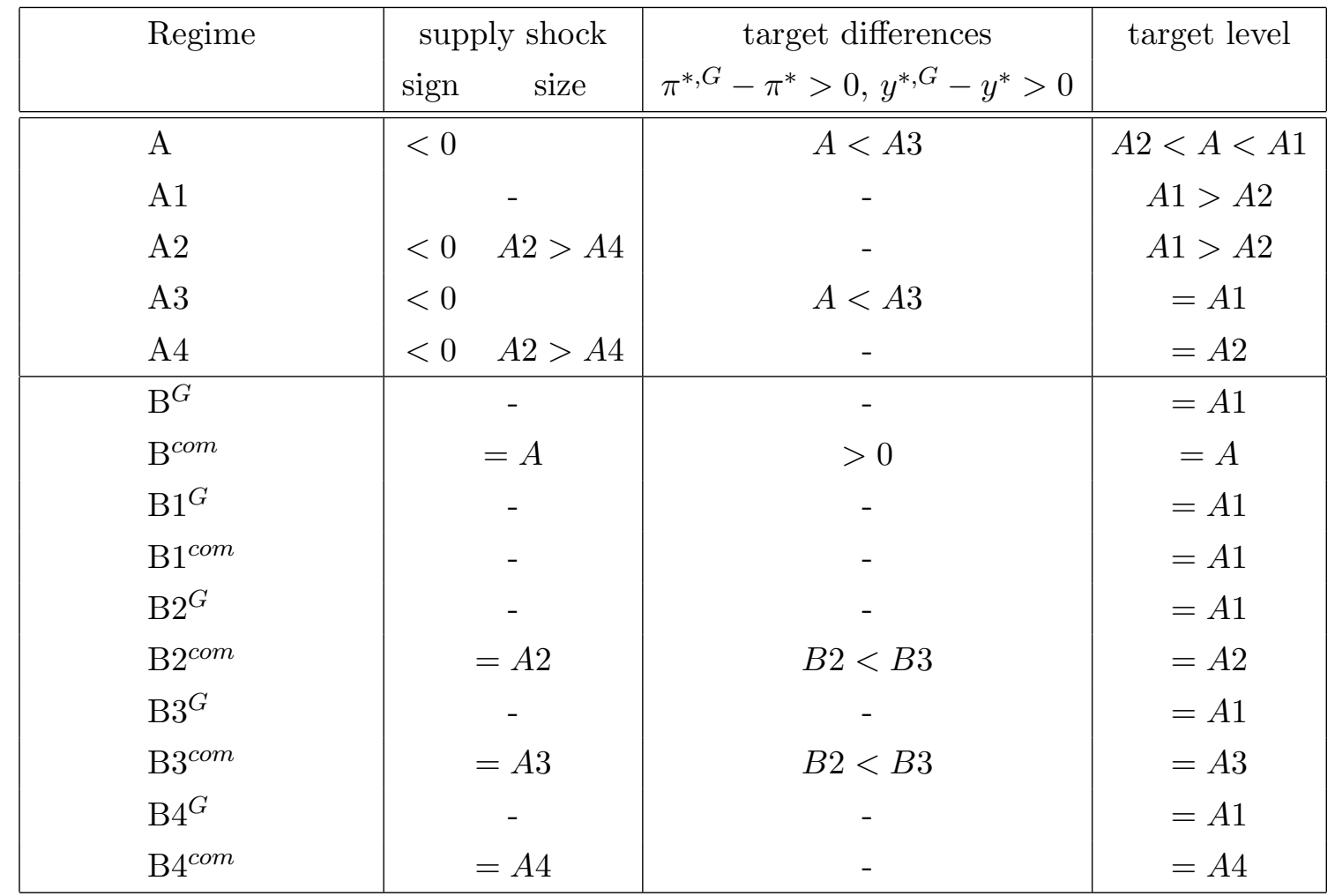

Table 4: Ranking of deficit outcomes across policy regimes 


\section{References}

Benigno, P., And M. Woodford (2003): "Optimal Monetary and Fiscal Policy: A Linear-Quadratic Approach," NBER Macroecnomics Annual, 18, 271-333.

Bernanke, B., And F. Mishkin (1997): "Inflation Targeting: A New Framework for Monetary Policy?," Journal of Economic Perspectives, 11(2), 97-116.

Blinder, A. S. (1997): "Is Government Too Political?," Foreign Affairs, 76(6), 115-126.

Briault, C., A. Haldane, and M. King (1997): "Independence and Accountability," in Towards More Effective Monetary Policy, ed. by I. Kuroda, chap. 10, pp. 299-326. Macmillan Press.

Buti, M., S. C. Eijffinger, And D. Franco (2003): "Revisiting the Stability and Growth Pact: Grand Design or Internal Adjustment?," CEPR Discussion Paper, No. 3692.

Calmfors, L. (2003): "Fiscal Policy to Stabilise the Domestic Economy in the EMU: What Can We Learn from Monetary Policy?," CESifo Economic Studies, 49(3), 319353.

Canzoneri, M. (1985): "Montery Policy Games and the Role of Private Information," American Economic Review, 75(5), 1056-1070.

Castellani, F. (2002): "A Model of Central Bank's Accountability," HEI Working Paper, No. 4.

Castellani, F., and X. Debrun (2005): "Central Bank Independence and the Design of Fiscal Institutions," International Finance, 8(1), 87-117.

Chari, V., and P. Kehoe (1999): "Optimal Fiscal and Monetary Policy," in Handbook of Macroeconomics, ed. by J. Taylor, and M. Woodford, chap. 26, pp. 1671-1745. Elsevier.

De HaAn, J., and S. C. Eijffinger (2000): "The Democratic Accountability of the European Central Bank: A Comment on Two Fairy-Tales," Journal of Common Market Studies, 38(3), 393-407.

Debelle, G., And S. Fischer (1994): "How Independent Should a Central Bank Be?," in oals, Guidelines and Constraints Facing Monetary Policymakers, ed. by J. Fuhrer, vol. 38 of Federal Reserve Bank of Boston Conference Proceedings, pp. 195-221.

Demertzis, M., A. Hughes-Hallet, and N. Viegi (1998): "Independently Blue? Accountability and Independence in the New European Central Bank," CEPR Discussion Paper, No. 1842. 
- (2004): "An Independent Central Bank Faced with Elected Governments," European Journal of Political Economy, 20, 907-922.

Dixit, A., And L. LAmbertini (2003): "Interactions of Commitment and Discretion in Monetary and Fiscal Policies," American Economic Review, 93(5), 1522-1542.

Eijffinger, S. C., And M. Hoeberichts (2002): "Central Bank Accountability and Transparency: Theory and Some Evidence," International Finance, 5(1), 73-96.

Fischer, S. (1994): "Modern Central Banking," in The Future of Central Banking, ed. by F. Capie, C. Goodhart, S. Fischer, and N. Schnadt, chap. 2, pp. 262-308. Cambridge University Press, Cambridge.

Herrendorf, B. (1998): "Inflation Targeting as a Way of Precommitment," Oxford Economic Papers, 50, 431-448.

Hughes Hallet, A., And J. LiBich (2006): "Central Bank Independence, Accountability and Transparency: Complements or Strategic Substitutes?," CEPR Discussion Paper, No. 5470.

Lohmann, S. (1992): "Optimal Commitment in Monetary Policy: Credibility versus Flexibility," American Economic Review, 82(1), 273-286.

Lucas, R., And N. Stokey (1983): "Optimal Fiscal and Monetary Policy in an Economy without Capital," Journal of Monetary Economics, 12, 55-93.

McCallum, B. T., and E. Nelson (2006): "Monetary and Fiscal Theories of the Price Level: The Irreconcilable Differences," NBER Working Paper, No. 12089.

Minailov, A. (2006): "Does Instrument Independence Matter under the Constrained Discretion of an Inflation Targeting Goal? Lessons from UK Taylor Rule Empirics," Department of Economics, University of Essex, mimeo.

Minov, I., And A. Sibert (2006): "Credibility and Flexibility with Independent Monetary Policy Committees," Journal of Money, Credit and Banking, 38(1), 23-46.

Nordhaus, W. (1994): "Policy Games: Coordination and Independence in Monetary and Fiscal Policies," Brookings Papers on Economic Activity, 2, 139-216.

RAmsey, F. (1927): "A Contribution to the Theory of Taxation," Economic Journal, $37,47-61$.

Sargent, T. J., And N. Wallace (1975): "Rational Expectations, the Optimal Monetary Instrument and the Optimal Money Supply Rule," Journal of Political Economy, $83,241-254$.

Schmitt-Groh, S., And M. Uribe (2004b): "Optimal Fiscal and Monetary Policy under Imperfect Competition," Journal of Macroeconomics, 26, 183-209. 
(2004a): "Optimal Fiscal and Monetary Policy under Sticky Prices," Journal of Economic Theory, 114, 198-230.

Svensson, L. E. O. (1997): "Optimal Inflation Targets, "Conservative" Central Banks, and Linear Inflation Contracts," American Economic Review, 87(1), 98-114.

UlLRich, K. (2007): "Introducing Instruments of Central Bank Accountability in a Monetary Union," Open Economies Review, 18, 239-262.

Walsh, C. E. (2003): Monetary Theory and Policy. MIT Press, Cambridge, MA, 2 edn.

Woodford, M. (2003): Interest Rates and Prices: Foundations of a Theory of Monetary Policy. Princeton University Press, Princeton and Oxford.

Wyplosz, C. (2005): "Fiscal Policy: Institutions versus Rules," National Institute Economic Review, 191, 70-84, National Institute of Economic and Social Research. 